Published in final edited form as:

Surg Oncol Clin N Am. 2010 April ; 19(2): 267-295. doi:10.1016/j.soc.2009.11.004.

\title{
Cystic Neoplasms of the Pancreas
}

\author{
Hop S. Tran Cao, MD ${ }^{a}{ }^{,}$, Benjamin Kellogg, MD ${ }^{b}$, Andrew M. Lowy, MD, FACS ${ }^{c}$, and Michael \\ Bouvet, MD ${ }^{d}$ \\ aDepartment of Surgery, Moores Cancer Center, University of California, San Diego School of \\ Medicine, 3855 Health Sciences Drive, La Jolla, CA 92093-0803, USA \\ bDepartment of Surgery, University of California, San Diego School of Medicine, 200 W. Arbor \\ Drive, San Diego, CA 92103, USA \\ 'Division of Surgical Oncology, Moores Cancer Center, University of California, San Diego School \\ of Medicine, 3855 Health Sciences Drive ML 0987, La Jolla, CA 92093-0987, USA \\ dDivision of Surgical Oncology, Department of Surgery, University of California, San Diego School \\ of Medicine, 3855 Health Sciences Drive, La Jolla, CA 92093-0987, USA
}

\begin{abstract}
Whereas pancreatic duct adenocarcinoma (PDA) is a well-studied (but still poorly understood) disease with a dismal prognosis, cystic neoplasms of the pancreas form a more recently recognized group of pancreatic tumors. They are diverse and variable in their pathologic characteristics, clinical course, and outcomes, ${ }^{1-3}$ although all portend a better overall prognosis than PDA. In recent years, with the improved sensitivity and increasing use of cross-sectional imaging in clinical practice, these lesions are more commonly identified, ${ }^{4}$ with many being discovered incidentally. Indeed, large radiological series using computed tomography (CT) or magnetic resonance imaging (MRI) have reported detection rates of pancreatic cystic lesions between $1.2 \%$ and almost $20 \%, 5,6$ approaching the $24.3 \%$ prevalence rate in an autopsy series by Kimura and colleagues. ${ }^{7}$ Although most of these lesions are pseudocysts, a significant portion consist of cystic neoplasms, which are estimated to represent $10 \%$ to $15 \%$ of all primary pancreatic cystic lesions. ${ }^{8}$ Given the growing clinical relevance of these tumors, a keen understanding of their natural history and pathophysiology is needed. This article reviews pancreatic cystic neoplasms, with a focus on the challenges encountered in their diagnosis and treatment.
\end{abstract}

\section{Keywords}

Pancreatic cystic neoplasm; Serous cystic neoplasm; Mucinous cystic neoplasm; Intraductal Papillary mucinous neoplasm

\section{Pancreatic Cystic Neoplasms}

Although pancreatic cystic neoplasms (PCNs) are often discussed together, it is important to realize that they are a heterogeneous group of tumors with wide-ranging malignant potential,

*Corresponding author. htrancao@ucsd.edu. 
from benign serous cystadenomas (SCAs) to malignant mucinous cystic neoplasms (MCNs) and invasive intraductal papillary mucinous neoplasms (IPMNs). ${ }^{9}$ They must be differentiated from one another and from other benign processes to ensure appropriate therapy. This distinction, however, is often difficult; misidentification can lead to incorrect management, with dire consequences. ${ }^{10}$ For this reason, some have advocated surgical resection of all suspected cystic neoplasms in medically fit patients. ${ }^{11,12}$ Although this aggressive approach minimizes the risk of allowing malignant lesions to progress undisturbed, it subjects patients with benign lesions to unnecessary and morbid operations. An increasing awareness of these tumors and a better understanding of their natural history, coupled with improvements in diagnostic tools, have made it possible to identify more discriminately those lesions that necessitate an operative intervention.

Between $40 \%$ and $75 \%$ of patients with PCNs experience no symptoms, ${ }^{13}$ with the lesion detected incidentally by abdominal imaging performed for the evaluation of another condition. When symptoms are present, they tend to be nonspecific. The differential diagnosis for a PCN is broad (Box 1), but must start with inflammatory pseudocysts, the most common cystic lesion of the pancreas. PCNs are misdiagnosed as pseudocysts in as many as $10 \%$ of cases, a significant figure, albeit improved from previously quoted rates. ${ }^{14,15}$ Pseudocysts form as a sequela of the autodigestive tissue necrosis following attacks of acute pancreatitis, and complicate chronic pancreatitis $30 \%$ to $40 \%$ of the time. A thorough history should detail previously documented episodes of pancreatitis or associated risk factors, including a history of alcohol abuse, biliary pathology, or trauma, and a family history of pancreatopathy. Pseudocysts may develop following pancreatectomy or can result from iatrogenic injuries to the pancreas during surgery on a nearby organ. The clinical picture alone is usually sufficient to make a diagnosis of inflammatory pseudocyst, but is further supported by the following features. Radiographically, a pseudocyst appears as a thick-walled, round, unilocular, well-circumscribed macrocyst that is usually associated with typical pancreatitis findings (eg, gland atrophy or calcification) on CT (Fig. 1). Ultrasound (US) reveals a well-defined echoic structure with distal acoustic enhancement, and possibly internal debris that moves in a dependent fashion with body positioning (Fig. 2). ${ }^{16} \mathrm{On}$ pathologic examination, pseudocysts contain necrotic/hemorrhagic debris and a turbid fluid rich in amylase and other pancreatic enzymes; their walls are made of inflammatory and fibrous tissue devoid of an epithelial lining, hence the name "pseudocysts."

Other nonneoplastic cystic lesions to consider in the differential diagnosis for PCNs include congenital cysts, retention cysts, infectious cysts, and lymphoepithelial cysts. Amongst PCNs, the most common entities (and the focus of this review) are serous cystic neoplasms (SCNs), MCNs, and IPMNs. The remaining members of this group consist of solid pseudopapillary tumors and the cystic variants of normally solid tumors, such as pancreatic ductal adenocarcinoma, neuroendocrine tumors, and acinar cell carcinoma. These tumors are not covered in this review. 


\section{SCNs}

\section{Introduction}

SCNs were first described in 1978 by Compagno and Oertel, ${ }^{1}$ who stressed the benign nature of these lesions compared with their mucin-producing counterpart. It is now known that SCNs account for approximately $30 \%$ of all PCNs, making them 1 of the most common primary cystic tumors of the pancreas. ${ }^{17}$ They are considered benign tumors, although several reports of a malignant version have led the World Health Organization (WHO) to classify 2 categories of SCNs: SCA and serous cystadenocarcinoma (SCAC). ${ }^{18}$ SCNs are typically diagnosed in women in their $60 \mathrm{~s}$, with the ratio of female/male patients approaching 3 to 4:1. ${ }^{19,20}$ SCNs can grow to large sizes, with a mean size between 5 and 7 $\mathrm{cm}$ at the time of diagnosis, ${ }^{21}$ and are nearly evenly distributed throughout the pancreas (head vs body and tail).22 Two major variants exist that differ macroscopically and radiographically, but that are otherwise similar in all other major aspects.

\section{Clinical Presentation}

In most SCN cases, the patient is asymptomatic and the lesion is detected incidentally during work-up for an unrelated process. When present, symptoms are usually vague and caused by mass effect, consisting principally of abdominal pain and discomfort and epigastric fullness. Weight loss, nausea, and vomiting occur much less frequently. Despite nearly $50 \%$ of SCNs occurring in the head of the pancreas, biliary obstruction causing jaundice is uncommon. ${ }^{23}$ Likewise, pancreatic duct obstruction leading to acute pancreatitis is rare. ${ }^{24}$ Symptomatology seems to be related to cyst size; Tseng and colleagues ${ }^{25}$ found in their series that cysts greater than $4 \mathrm{~cm}$ in size were 3 times more likely to be symptomatic than cysts smaller than $4 \mathrm{~cm}$.

A comparative review of malignant and benign SCNs found that patients with SCACs tend to be older by an average of 5 years at the time of diagnosis ( $66 \mathrm{vs} 61$ years), and they were more likely to be symptomatic, with $86 \%$ of patients experiencing symptoms compared with $66 \%$ of patients with SCAs. ${ }^{26}$

\section{Pathophysiology}

Unlike MCNs and IPMNs, SCNs are generally regarded as benign lesions. However, this thinking has been challenged by several case reports of SCNs associated with synchronous or metachronous metastatic lesions, most commonly to the liver. ${ }^{27,28}$ Strobel and colleagues ${ }^{26}$ calculated the prevalence of SCACs to be $3 \%$ of all serous cystic tumors, although they recognize that this figure is likely an overestimation caused by publication bias; the investigators go on to postulate that SCNs, like the mucin-producing cystic neoplasms, may undergo a stepwise benign to malignant progression. This theory is not fully supported by the histologic findings, as less than half of all reported SCACs show any potential signs of malignant growth, such as vascular and perineural invasion or local invasion into the stomach or spleen. Moreover, these criteria are currently not considered diagnostic for malignancy. Instead, the diagnosis of SCAC is established only on documentation of either synchronous or metachronous extrapancreatic metastases. ${ }^{29}$ Even in these instances, primary and metastatic lesions are often histologically indistinguishable 
from benign SCAs, causing some to question whether this is a metastatic neoplasm or a multifocal disease. ${ }^{30}$

Several SCNs have been found to coexist with either another extrapancreatic neoplasm ${ }^{31}$ or other distinctly different pancreatic neoplasms, such as ductal adenocarcinomas or islet cell tumors. ${ }^{32}$ Patients with von Hippel-Lindau (VHL) disease are at increased risk of developing SCNs, accounting for $15 \%$ to $30 \%$ of all such lesions ${ }^{33}$; referred to as VHLassociated cystic neoplasms, they have a propensity to affect the pancreas diffusely and lack a gender predilection. ${ }^{34}$

A molecular study by Moore and colleagues ${ }^{35}$ identified loss of heterozygosity (LOH) at chromosome 10q in nearly half of microcystic SCNs, and LOH at chromosome 3p in $40 \%$ of the cases. The latter is the location for the VHL gene, and chromosomal alterations of this particular gene have been reported in a large number of SCAs. ${ }^{36}$ Strobel and colleagues ${ }^{26}$ implicated the role of Ki-67, a proliferation marker, and p53 in SCACs.

\section{Pathology/Classification}

SCNs are characterized by serous fluid-filled cysts lined by a single layer of uniform, cuboidal epithelial cells with round, centrally located nuclei and glycogen-rich clear cytoplasm (Fig. 3). These cells stain positively for periodic acid-Schiff reaction and are believed to originate from centroacinar cells. ${ }^{37}$ Two major morphologic variants of SCNs exist that differ in their radiographic and gross appearance, but share the histologic features mentioned earlier. The polycystic microcystic form is more common, accounting for $70 \%$ of all SCNs. It often presents as a spongy, bosselated, well-circumscribed collection of multiple small cysts $(<2 \mathrm{~cm})$ separated by a central fibrous scar that may contain calcifications arranged in a characteristic stellate pattern. ${ }^{13}$ The designation "honeycomb pattern" is sometimes attributed to those tumors with cysts too numerous and small to be discerned as individual cysts on imaging. The second, and much less common variant of SCNs, is the oligocystic form, which has fewer, but larger cysts. ${ }^{38}$ For this reason, these are sometimes called macrocystic serous neoplasms. Oligocystic serous neoplasms occur predominantly in the head of the pancreas. ${ }^{39}$ As mentioned earlier, the rare SCACs are diagnosed only by the presence of extrapancreatic metastases, but otherwise are histologically similar to the benign SCAs. As a group, SCNs typically do not communicate with the pancreatic ductal system, and have a thin clear wall that separates easily from the surrounding tissue, without inflammatory or fibrous adherence. ${ }^{21}$

\section{Diagnosis}

Diagnosis of SCNs can usually be achieved radiographically. Most commonly, these lesions are first evaluated with $\mathrm{CT}$, and, in the case of polycystic microcystic tumors, appear as a nonenhancing mass containing multiple small cysts separated by internal septations, resembling a honeycomb (Fig. 4). The identification of a central starburst calcification is pathognomonic of SCN. This finding is the radiographic manifestation of the stellate calcification pattern characteristic of the central fibrous scar of SCNs, but occurs only $30 \%$ of the time. ${ }^{40}$ Rarely, the cysts are so small that they cannot be distinguished individually, giving the tumor a solid appearance that is of low attenuation on CT. ${ }^{13}$ The oligocystic 
variant, on the other hand, presents a greater diagnostic challenge, because it can resemble either pseudocysts or, more importantly, MCNs. ${ }^{41}$ In this situation, Kim and colleagues ${ }^{42}$ have identified another CT feature that can assist in the diagnosis: oligocystic SCNs have a distinctive lobulated contour that distinguishes them from MCNs. Location of the mass within the pancreas is helpful also, because oligocystic SCNs are usually found in the head, whereas MCNs tend to grow in the body and tail of the pancreas. It is estimated that, in the appropriate clinical setting, $90 \%$ to $95 \%$ of SCNs can be accurately diagnosed based on a combination of an indolent course with findings of stromal hypervascularity, a predominance of small cystic areas, and lack of metastases or local invasion on imaging. ${ }^{17}$

For those cases in which a diagnosis remains unclear, other modalities can be used to supplement CT. MRI can show the presence of fluid within the septations of a spongelike mass that appears hyperintense on T2-weighted images; this modality, however, has the disadvantage of being insensitive to calcifications. ${ }^{43}$ On endoscopic ultrasound (EUS), SCNs are typically found to have multilobulated borders and an internal honeycomb architecture, although they lack posterior acoustic shadowing. ${ }^{44}$ Furthermore, EUS has the additional advantage of allowing sampling of cyst content and cyst wall for cytology and biochemical analysis via fine-needle aspiration (FNA). Often, the cytologic examination of the cyst fluid is nondiagnostic because of the low cellular yield of FNA ${ }^{45}$; however, Huang and colleagues ${ }^{46}$ point out that this scant cellularity can have high predictive value for SCNs if associated EUS morphology is consistent with the diagnosis. When cells are recovered, they stain positively for periodic acid-Schiff reaction for glycogen, negatively for mucin, and lack immunoreactivity for the cytokeratins AE1 and AE3. ${ }^{47}$ Cyst fluid analysis should consistently yield a low amylase level, distinguishing SCNs from pseudocysts. ${ }^{48}$ Similarly, cyst fluid levels of tumor markers such as carcinoembryonic antigen (CEA) and carbohydrate antigen 19-9 (CA19-9) are typically low, differentiating SCNs from mucinous neoplasms. ${ }^{49}$ Serum tumor markers have little to offer in the diagnosis and are not routinely obtained; when increased, serum CEA or CA19-9 levels point to a different diagnosis. Likewise, endoscopic retrograde cholangiopancreatography (ERCP) and magnetic resonance cholangiopancreatography (MRCP) are seldom useful in the work-up of SCNs because these lesions, like MCNs, generally do not communicate with the pancreatic ductal system.

\section{Management}

The most crucial aspect in the management of SCNs is definitively establishing the correct diagnosis. Once this diagnosis is achieved, the approach to patients with SCNs should be selective. Most investigators agree that surgery should be offered for patients who experience symptoms, rapid tumor growth, or changes in radiographic appearance, or in whom a definitive diagnosis cannot be obtained.$^{50}$ In contrast, some investigators have advocated surgical resection of all cystic neoplasms except in the case of an SCN diagnosed with certainty in older patients or poor surgical candidates. ${ }^{44,51}$ More recently, Strobel and colleagues ${ }^{26}$ have cited the risk of malignancy (SCAC) in support of this aggressive approach. Given the generally benign nature of the disease, this strategy seems excessive. Katz and colleagues ${ }^{52}$ consider operative intervention to be a reasonable option for tumors whose size is greater than $4 \mathrm{~cm}$, pointing out the report by Tseng and colleagues ${ }^{25}$ that these tumors grow more quickly than smaller lesions. In the authors' practice, tumor size itself is 
not an indication for surgery, but does usually coincide with the presence of symptoms and rapid tumor growth. These factors, along with the increasingly rare cases in which there remains concern for malignancy, form the only firm criteria for which surgical intervention is warranted in patients with SCAs. If these factors are absent, nonoperative management with observation alone, with at least yearly imaging with high-quality CT, is safe. In separate series, Bassi ${ }^{53}$ and Le Borgne ${ }^{19}$ and their colleagues followed conservatively managed patients with welldocumented SCAs for 69 and 38 months, respectively, and found that none developed significant changes requiring surgery.

When surgery is indicated, a nonradical, but complete, resection is curative, and long-term survival is excellent, as would be expected for a mostly benign entity. Extended resection and lymphadenectomy are unnecessary and morbid. A lesion in the tail of the pancreas is best addressed by a spleen-preserving distal pancreatectomy ${ }^{54}$ using a laparoscopic or open approach, whereas a lesion in the head can be removed by pylorus-preserving pancreaticoduodenectomy. ${ }^{55}$ Likewise, SCAs in the neck and proximal body of the pancreas can be resected via either a distal-subtotal or a central pancreatectomy. ${ }^{56}$ Some investigators have even advocated more limited, localized resection. Talamini and colleagues ${ }^{57}$ first described the use of enucleation for benign PCNs in 1998, demonstrating in their series that this operation was associated with shorter operating time and less blood loss, but with a higher incidence of fistula formation, yet equal rates of major complications, than anatomic resections. Kiely and colleagues ${ }^{58}$ modified the technique by using intraoperative ultrasound to facilitate identification of the pancreatic duct and permit safe closure of the defect after enucleation, successfully reducing rates of fistula formation to levels achieved for anatomic pancreatectomies. This technique led the investigators to advocate the use of enucleation for small benign cystic neoplasms. The decision to perform this procedure should be based on the surgeon's skills and comfort level, and should be pursued only in benign cystic lesions, as it is considered by most a suboptimal operation for malignancies.

Although most investigators agree that postoperative surveillance is unnecessary from an oncologic standpoint following complete resection, Galanis and colleagues ${ }^{20}$ raise the concern for metachronous metastases in a small subset of patients with SCNs. They advise that patients in whom lesions are found on pathology to exhibit locally aggressive behavior (ie, extension beyond the pancreas into an adjacent organ or local invasion into a blood vessel) despite negative surgical margins may require additional imaging follow-up. However, cases of metachronous metastatic or recurrent disease are so rare that postresection surveillance for SCNs remains unwarranted.

\section{MCNs}

\section{Introduction}

In 1978, Compagno and Oertel, ${ }^{2}$ who had produced a detailed histopathologic report on SCNs that same year, were the first to describe clearly a set of mucin-producing neoplasms in the pancreas that harbored either overt or latent malignancy. It is now known that these tumors are composed of 2 distinct entities: MCNs and IPMNs. Although they share certain characteristics, such as mucin production and a definite malignant potential, these lesions differ in numerous ways, including age and gender distribution, location in the pancreas, and 
symptomatology. MCNs are generally recognized as (pre)malignant lesions, and when diagnosed, generally warrant surgical resection. They account for $10 \%$ to $45 \%$ of all PCNs, ${ }^{59}$ and are localized in the pancreatic body and tail in $90 \%$ of cases.

MCNs are found almost exclusively in women, with few cases reported in men throughout the literature. ${ }^{60,61}$ Affected patients vary widely in age, but in general are younger than patients with SCNs or IPMNs, with the median age at the time of diagnosis of 50 years. Patients with malignant MCNs (mucinous cystadenocarcinoma [MCAC]) are older than their benign MCN-bearing counterpart, by an average of 15 years, reflecting the process of malignant transformation recognized for this disease. ${ }^{62}$ Gender distribution and anatomic location seem to differ between benign and malignant lesions also. The large disparity in gender distribution is less pronounced for malignant $\mathrm{MCNs},{ }^{63}$ while a review of the literature by Le Borgne and colleagues ${ }^{64}$ found that $46 \%$ of 156 MCACs were located in the head of the pancreas.

\section{Clinical Presentation}

Symptoms are more common in MCNs than in SCNs, being present $60 \%$ of the time. They are usually nonspecific and caused by compression rather than invasion of adjacent tissue. ${ }^{34}$ Most commonly, abdominal discomfort and pain, nausea, and dyspepsia are reported. A previous history of pancreatitis is reported in $10 \%$ to $20 \%$ of patients ${ }^{40}$; in these instances, the clinician may confuse the neoplasm for a pseudocyst. Obstructive jaundice is rare because MCNs are predominantly found in the pancreatic body and tail, but does complicate $25 \%$ to $54 \%$ of those MCNs located in the pancreatic head. ${ }^{21}$ Rarely, a firm, round abdominal mass can be palpated in the left upper quadrant that is often tender and moves with respiration. ${ }^{2}$ Generally, however, the physical examination is unremarkable.

The presence of symptoms is highly suggestive of malignancy. Nearly all patients with malignant MCN are symptomatic ${ }^{65}$; in particular, the presence of diabetes mellitus was noted to be strongly associated with malignancy. ${ }^{66}$ Other symptoms that may indicate malignancy include obstructive jaundice, anorexia, weight loss, and signs of portal hypertension. Absence of symptoms, however, does not exclude a diagnosis of malignant MCN. A report by Fernandez-del Castillo and colleagues ${ }^{59}$ showed that half of asymptomatic, incidentally discovered MCNs harbored either borderline or frank malignancy.

\section{Pathophysiology}

Previously collectively classified in the category of mucin-producing cystic neoplasms, MCNs and IPMNs are now known to differ in multiple ways, clinically and pathologically. The major histologic difference between the 2 entities is the presence of ovarian-type stroma in MCNs. This feature has now been established as a key defining characteristic without which a diagnosis of MCN cannot be rendered, according to WHO and the Armed Forces Institute of Pathology. ${ }^{18,67}$ This subepithelial stroma shares the same histologic and immunohistochemical profile as that of ovaries, ${ }^{68}$ and may provide a clue about the origin of these tumors. The "genital ridge theory" proposes that MCNs arise from cellular stromal 
elements of the genital ridge that may be associated with the pancreas ${ }^{60}$ and could explain the female predominance among MCN patients.

MCNs may undergo a slow process of malignant degeneration in a period of years, from adenoma to borderline malignancy to frank adenocarcinoma, as suggested by the common concurrence of atypia, dyplasia, carcinoma in situ, and invasive carcinoma within the same tumor. ${ }^{69}$ Furthermore, the significant age difference between patients with benign and malignant MCNs is consistent with this concept of malignant transformation. Biomolecular studies have shown that the K-ras gene undergoes early mutations in MCNs and does so more frequently with malignancy, leading some investigators to argue that presence of K-ras mutations in the cyst fluid can be used as a marker for malignancy. ${ }^{70}$ Likewise, nuclear p53 immunoreactivity indicates malignant changes. DPC4 gene expression is lost in invasive MCNs. ${ }^{60}$

\section{Pathology/Classification}

Macroscopically, MCNs are solitary round tumors that have a smooth surface and a fibrous pseudocapsule. They are composed of a few (sometimes only 1) thick-walled macrocysts that are most often multilocular, with internal septations and sometimes an eccentric solid component. Less commonly, the cysts are unilocular, with a smooth glistening internal surface. MCN cysts contain a thick viscous fluid, and in many instances, necrotic, hemorrhagic, or mucinous debris also. ${ }^{71}$ They generally do not communicate with the pancreatic ductal system. ${ }^{37}$ So few cases of communicating MCNs are reported in the literature ${ }^{64}$ that some investigators have questioned whether they might have been IPMNs instead. ${ }^{72}$ As a general guideline, presence of a communication favors the diagnosis of IPMN, but does not exclude a diagnosis of MCN.

Microscopically, MCNs are defined by the presence of a distinctive subepithelial ovariantype stroma that distinguishes them from IPMNs. This stroma is histologically and immunohistochemically similar to that of ovaries, including the expression of estrogen and progesterone receptors and human chorionic gonadotropin. ${ }^{68}$ It forms a layer of densely packed cells with oval nuclei and spindled cytoplasm arranged in long fascicles that are admixed with luteal-type cells. Overlying this stroma are mucin-secreting, columnar epithelial cells (Fig. 5) exhibiting a wide range of dysplasia, the degree of which combines with presence of tissue invasion to classify MCNs as adenomas, borderline tumors, and adenocarcinomas. ${ }^{18}$ Because MCNs can contain focal areas of malignancy interspersed with otherwise benign epithelium within a single tumor, they are classified by the most aggressive histologic finding. It is estimated that the prevalence of invasive carcinoma in MCNs varies between $6 \%$ and $36 \% .{ }^{73,74}$

In addition to the common coexistence of benign and malignant areas within the same tumors, MCNs also have a propensity to have a discontinuous epithelial lining, with areas of denuded cyst wall devoid of cells. This occurs in $70 \%$ of cases and presents a significant source of sampling errors. ${ }^{69}$ For these reasons, a complete histologic examination of the entire specimen on resection is necessary to establish an accurate diagnosis. Several pathologic features can be helpful in distinguishing malignant from benign lesions. Multilocularity, location in the head of the pancreas, and presence of papillary projections 
and sarcomatous nodules within the stroma indicate, but do not diagnose, MCACs. ${ }^{75}$ Likewise, presence of an eccentric solid component, a peripheral calcification pattern, and tumor size greater than $3 \mathrm{~cm}$ are concerning for malignancy, ${ }^{76}$ although tumors less than 3 cm still carry a near $20 \%$ malignancy rate. ${ }^{77}$

\section{Diagnosis}

$\mathrm{CT}$ is considered an excellent first test in the work-up of a cystic lesion of the pancreas, as it allows characterization of the cyst(s) and the pancreas. In MCNs, the mass will appear as a thick-walled, usually septated macrocyst with smooth sharp boundaries (Fig. 6), surrounded by noninflamed pancreatic tissue that can assist in differentiating it from a pancreatic pseudocyst. ${ }^{42}$ Although MCNs do not generally communicate with the pancreatic duct, they can obstruct the ductal system by direct compression of the adjacent pancreatic parenchyma, leading to pancreatic duct dilation, a finding more often associated with IPMNs. ${ }^{21}$ However, detection of a communication between the dilated pancreatic ductal system and the lesion should favor a diagnosis of IPMN. CT may also reveal the presence of papillary excrescences or mural nodules, an eccentric solid component, and, in up to $20 \%$ of cases, calcifications distributed in an eggshell pattern within the peripheral cyst walls. ${ }^{40}$ All of these radiographic findings, along with evidence of pericystic reaction, invasion of surrounding vascular structures, extrahepatic biliary obstruction, metastatic cystic liver lesions, and ascites, are highly suggestive of invasive disease. ${ }^{21}$ However, definite preoperative differentiation between benign and malignant MCNs is impossible in most cases. ${ }^{62}$

MRI, especially when combined with MRCP, confers the advantage of more clearly characterizing the morphologic features of the cysts, and possibly identifying a communication between the cysts and the pancreatic ductal system. In that respect, this imaging modality can be helpful in distinguishing MCNs from IPMNs. Likewise, ERCP, the most sensitive tool for detecting a duct-cyst communication, is useful only in differentiating between the 2 types of mucin-producing neoplasms. ${ }^{78}$ It otherwise has little to add in the evaluation of MCNs. For this reason, and because MRCP can provide the same information in a noninvasive manner, ERCP is not routinely recommended as a primary diagnostic tool in the work-up of PCNs, except when IPMN is suspected. EUS, on the other hand, can be an important adjunct to crosssectional imaging by providing detailed images of the cyst wall and the internal architecture of the cystic components. ${ }^{79}$ Macrocystic multilocular MCNs appear on US as a sharply defined mass surrounded by a thickened wall, containing internal thin septae and calcifications. The unilocular variant is much less specific in appearance and can resemble other cystic lesions.

An additional advantage of EUS is that it permits cyst aspiration and sampling of the tumor. ${ }^{80}$ The decision to perform cyst biopsies comes with the theoretic risk of tumor seeding, although in a series by Le Borgne and colleagues ${ }^{19}$ none of the 21 patients with MCAC who received FNA of their lesion was found to have malignant cell seeding along the needle tract. This risk may be minimized when FNA is performed via EUS instead of percutaneously. ${ }^{81}$ Cyst wall biopsies are unreliable and subject to sampling errors because of the heterogeneity of MCN epithelial lining, both in continuity and uniformity, resulting in 
high rates of false-negative reports or erroneous reports of noninvasive disease when focal areas of invasion are present. ${ }^{52}$ Aspirated cyst fluid can be helpful in reaching the correct diagnosis when it is sent for cytology and biochemical analysis. One limitation to the cytologic evaluation is that cellular yield from FNA can often be low and nondiagnostic. Even when cells are recovered, the sensitivity of cyst fluid cytology for PCNs is reported to be only around $50 \%,{ }^{49}$ although more recently, a study by Moparty and colleagues ${ }^{82}$ reported an EUS-FNA diagnostic accuracy rate of 93\%. These investigators attributed this success rate partly to having a cytopathologist assess specimen adequacy during aspiration of the cyst by the endoscopist. FNA cytology is of reliable diagnostic value only when obviously malignant cells are recovered, because absence of such cells does not exclude a malignant process. The characteristic cytology of MCN consists of honeycomb sheets and clusters of mucin-containing columnar cells with, rarely, small papillary sheets on a background of abundant mucin. The cells stain positively for mucin, a finding that is sensitive for mucin-producing neoplasms, but cannot differentiate between invasive and noninvasive disease. ${ }^{83}$ Likewise, increased fluid viscosity ( $\left.>1.6\right)$ may help to distinguish MCNs from SCNs and pseudocysts, but does not give information regarding invasiveness of the lesion. ${ }^{48}$ Furthermore, measurement of viscosity can be subjective and cumbersome, somewhat limiting its usefulness. ${ }^{84}$

The other, perhaps more useful, aspect of cyst fluid analysis consists of assessing fluid levels of amylase and tumor markers. An increased amylase level indicates that the lesion communicates with the ductal system and is most often associated with pseudocysts and IPMNs. A high value can also be detected in the occasional MCN that communicates with the pancreatic ducts. Diagnostically, amylase level does not accurately discriminate the different types of cysts. ${ }^{14}$ Several tumor markers have been evaluated in the work-up of PCNs also, including CA19-9, CA-125, CA72-4, and CEA. By far, CEA is the best studied and most clinically applicable marker, with several investigators having advocated different cut-off values to assist in differentiating mucinous from nonmucinous lesions. ${ }^{48,49,85}$ As the cut-off value increases, specificity improves at the expense of decreasing sensitivity. Although no standardized value exists, cyst fluid CEA level greater than $192 \mathrm{ng} / \mathrm{mL}$, as reported by Brugge and colleagues, ${ }^{85}$ achieves the greatest diagnostic accuracy (79\%) for mucinous neoplasms, with diagnostic sensitivity of $75 \%$ and specificity of $84 \%$. These investigators showed that CEA level alone achieved greater diagnostic accuracy than cytology, cyst morphology, fluid CA19-9 level, or any combination thereof. CEA level may also help distinguish invasive from noninvasive MCN, with values greater than $6000 \mathrm{ng} / \mathrm{mL}$ being highly suggestive of MCAC. ${ }^{48}$ On the opposite end of the spectrum, a lesion with cyst fluid CEA level less than $5 \mathrm{ng} / \mathrm{mL}$ is highly unlikely to be an $\mathrm{MCN} .{ }^{49}$ It is important, however, to stress that these values are merely guidelines and not definitive diagnostic criteria.

Positron emission tomography has been shown to be helpful in distinguishing malignant from benign lesions, especially when combined with CT. ${ }^{86}$ However, its exact role in the evaluation of MCNs, and PCNs in general, has yet to be clearly established. 


\section{Management}

Given the risk of overt or latent malignancy and the inability to definitively distinguish benign from malignant lesions preoperatively, most surgeons agree with the consensus guidelines set by the International Association of Pancreatology that the primary treatment of MCNs should be surgical resection whenever possible. ${ }^{87}$ This aggressive approach is warranted because it is thought that most benign MCNs can undergo malignant transformation and develop into MCACs, at which time they have low resectability and poor prognosis. ${ }^{69,75}$ Observation may be a reasonable option for elderly patients or those with severe comorbidities, especially when the lesion is small and lacks features suspicious for malignancy.

Because most MCNs are localized in the pancreatic tail, the treatment of choice is a distal pancreatectomy, a safe procedure with low morbidity and mortality. ${ }^{88}$ The spleen can be preserved unless invasive disease is either suspected or detected at the time of surgery. ${ }^{89}$ Likewise, limited pancreatic resections for tumors located in other parts of the pancreas are acceptable, and possibly preferred, when benign disease is diagnosed, including duodenumpreserving pancreatic head resections for lesions in the head of the pancreas ${ }^{90}$ and middle pancreatectomies for those in the body. ${ }^{56}$ However, when the diagnosis is uncertain or malignancy is suspected, a complete resection, namely pancreaticoduodenectomy or distal pancreatectomy with splenectomy, is required. Because MCNs, even when invasive, tend to have easily discernible boundaries and generally do not harbor microscopic extensions into the uninvolved-appearing pancreas, obtaining negative margins is usually achievable without the need for frozen sections, except when a suspiciously firm area is found near the margin. ${ }^{87}$

Rarely, MCACs can invade surrounding structures, necessitating an even more extensive resection to achieve negative margins. ${ }^{19}$ Moreover, when metastases are found that are resectable, they should be removed together with the tumor. ${ }^{91}$ The role of extended lymphadenectomy, however, remains unclear, but should be reserved for invasive disease. Lymphatic involvement, which decreases survival, is much less common for MCAC than for ductal adenocarcinoma. ${ }^{92}$ As noted earlier, nonanatomic resections such as enucleation are considered to be inadequate oncologic procedures, and are acceptable treatment options only for benign lesions. In light of the limitations in preoperative and even intraoperative recognition of an underlying invasive disease, enucleation is generally not an appropriate operation in the treatment of MCNs.

Survival after resection of MCNs is most strongly prognosticated by extent of invasion. ${ }^{60}$ Complete excision of noninvasive MCNs, including those with carcinoma in situ, is curative and associated with excellent outcomes, approaching $100 \%$ 5-year survival rates. ${ }^{13}$ Unlike IPMNs, which can be multifocal and affect distant parts of the pancreas, MCNs are solitary lesions that, when lacking any invasive component, do not recur after complete resection. ${ }^{73,74}$ For this reason, surveillance imaging is probably unnecessary for noninvasive MCNs. When invasion has occurred, however, the outcomes change drastically. Recurrence after resection of invasive MCNs is frequent and portends a poorer prognosis. Although several early studies reported favorable 5-year actuarial survival rates after resection of MCAC to be more than $50 \%$ and up to $70 \%,{ }^{15,40,93}$ closer inspection of the data specifically 
detailing presence of invasion reduces this number to the $15 \%$ to $33 \%$ range for invasive disease, as reported by Sakorafas and Sarr. ${ }^{21}$ Prognosis for unresectable MCAC is dismal, resembling that for unresected ductal adenocarcinoma. ${ }^{91}$ The current recommended surveillance program for resected invasive MCNs consists of close monitoring of patients for local recurrence and distal metastasis, with regular physical examinations and crosssectional imaging at least every 6 months. ${ }^{87}$ The frequency of imaging can be reduced after a few years if no change is observed. As a guideline, patients with resected invasive MCNs should be followed according to the same institutional protocol and schedule as patients with resected ductal cancer.

\section{IPMNs}

\section{Introduction}

IPMNs were first described in 1982 by Ohhashi and colleagues, ${ }^{3}$ who reported 4 cases of patients who had favorable outcomes with pancreatic cancer and shared several clinical features, including a dilated main pancreatic duct, a patulous ampulla of Vater orifice, and mucus secretion. Since then, IPMNs have been further categorized and defined as a distinct clinical entity. WHO first divided mucin-producing pancreatic tumors into intraductal papillary mucinous tumors and mucinous cystic tumors in $1996,{ }^{18}$ and subsequently renamed them IPMNs and MCNs in 2000. ${ }^{94}$ With the increasing use of high-resolution abdominal imaging and improved recognition of the disease, IPMN diagnosis has increased in the last 2 decades ${ }^{21,95}$; by the latest estimates, they are believed to represent $25 \%$ of PCNs and account for an increasingly large proportion, up to $20 \%$ in some series, of resections for pancreatic neoplasms. ${ }^{95,96}$

IPMNs are typically diagnosed in patients between the ages of 60 and 70 years. As with MCNs, invasive neoplasms are associated with advancing age, with a 5- to 7-year lag time between benign and malignant disease, reflecting the process of malignant degeneration in the disease. ${ }^{97}$ IPMNs affect men and women with equal incidence and are localized in the head of the pancreas $50 \%$ of the time. Of the remaining half, almost $80 \%$ are multifocal, affecting multiple distinct or continuous areas of the pancreas. ${ }^{98}$

\section{Clinical Presentation}

Approximately $25 \%$ of patients found to have IPMNs are asymptomatic at presentation, with the lesion detected incidentally on imaging for other indications. ${ }^{99}$ Most patients do experience symptoms that tend to be nonspecific and include vague abdominal pain, nausea, vomiting, and back pain. Up to $20 \%$ of patients with IPMN report a long-standing history of recurrent attacks of acute or chronic obstructive pancreatitis secondary to intermittent obstruction of the pancreatic duct with mucus plugs or by the tumor itself. Similarly, biliary obstruction can occur by mucus plugging or external compression of the distal common bile duct or ampulla. As such, symptoms of pancreatic exocrine or endocrine insufficiency, and those of biliary obstruction, can be encountered, including steatorrhea, diarrhea, weight loss, jaundice, and new onset or worsening diabetes mellitus, with the last 3 highly associated with invasive disease. ${ }^{97,100}$ Weight loss is likely the result of a combination of 
malabsorption from exocrine insufficiency, food avoidance because of abdominal pain, and cachexia-inducing neoplastic factors released by the tumor. ${ }^{101}$

Although the presence of symptoms indicates invasive disease, ${ }^{102}$ lack of symptoms does not exclude it, especially in the main-duct variant of IPMNs. In a series of 140 patients with main-duct IPMN, Salvia and colleagues ${ }^{97}$ found that $29 \%$ of those found to have either high-grade dysplasia or invasive carcinoma were asymptomatic. In branch-duct IPMN, symptoms seem to be more strongly correlated with invasiveness; Sugiyama and colleagues ${ }^{102}$ found no invasive disease in all 17 patients in their cohort of branch-duct IPMN who were asymptomatic, although presence of symptoms was not identified as an independent predictive factor in multivariate analysis.

\section{Pathophysiology}

The cause and natural history of IPMNs remain unclear. Although there does not seem to be a familial or genetic predisposition for the development of IPMNs, cases detailing an association with inherited syndromes such as Peutz-Jeghers syndrome, familial adenomatous polyposis, and familial pancreatic cancer syndromes have been reported. ${ }^{99}$ In addition, there is evidence that patients with IPMN are at increased risk of developing synchronous or metachronous primary extrapancreatic cancers, the most common of which are gastric adenocarcinoma and colorectal cancer. ${ }^{103,104}$

The current belief is that IPMNs undergo a slow stepwise malignant progression from lowgrade dysplastic lesions into invasive carcinoma by the accumulation of mutations, reminiscent of the well-defined adenoma-carcinoma sequence for colon and pancreatic cancer. This belief is supported by the significant age difference between patients with benign IPMNs, with either low- or moderate-grade dysplasia, and those with malignant IPMNs, with either high-grade dysplasia or invasive carcinoma. It is also common to find varying degrees of cytoarchitectural atypia within a single IPMN. ${ }^{99,105}$ Although IPMNs arise from the pancreatic ducts and share a similar adenoma-carcinoma sequence as that of pancreatic ductal adenocarcinoma, the 2 entities are distinct in their genetic alterations. Nearly all IPMNs express DPC4 (deleted in pancreatic cancer), whereas less than half of ductal carcinomas do. ${ }^{95}$ Moreover, the two differ in the mucin type they secrete, with ductal adenocarcinomas producing mucin glycoprotein MUC1 and IPMNs expressing MUC2. ${ }^{106}$

In addition to DPC4, several molecular abnormalities believed to be responsible for this malignant transformation in IPMNs have been described. K-ras mutations are present in about one-half of IPMN cases, but whether these mutations are positively associated with neoplastic transformation remains the subject of debate because of conflicting reports. ${ }^{107,108}$ Telomerase activity, on the other hand, has been shown to correlate strongly with malignant degeneration, with Uemura and colleagues ${ }^{109}$ detecting telomerase activity in $100 \%$ of malignant IPMNs and in 0 of 5 benign IPMNs. Similarly, LOH of the p16 gene is seen with greater frequency with increasing degrees of histologic atypia, whereas LOH of the p53 gene occurs late in the IPMN progression toward cancer, being found in only invasive lesions in 1 series. ${ }^{110}$ A recent study by Fritz and colleagues ${ }^{111}$ identified several recurrent cytogenetic alterations characteristic of moderate- and high-grade IPMNs that differed from those found in ductal adenocarcinoma. 


\section{Pathology/Classification}

IPMNs are grossly visible tumors that are characterized by cystic dilation of either the main pancreatic duct or major branch ducts, associated with papillary projections and copious mucin secretion, ${ }^{3}$ and are believed to originate from ductal epithelium. The areas of ductal dilation are often filled with mucin, and can be single or multifocal, segmental or diffuse. Often, when the main pancreatic duct is involved, the ampulla of Vater is also dilated, with mucin seen protruding through a patulous, so called fish-mouth, papilla on endoscopy, a pathognomonic finding seen in only $30 \%$ of patients with IPMN. ${ }^{21,112}$ Morphologically, IPMNs differ from MCNs in their appearance, with the former having an ill-defined, irregular contour and the latter having a round, well-demarcated contour formed by a thick fibrous capsule. A second distinctive characteristic is that the cysts in IPMN communicate with the pancreatic ductal system, whereas those in MCN do not.

Histologically, IPMNs lack the ovarian-type stroma characteristic of MCNs and are lined with tall, columnar, mucin-producing epithelial cells that can display a broad spectrum of dysplastic changes (Fig. 7). Consequently, IPMNs can be classified based on the degree of cytologic and architectural atypia and presence of invasion as benign, including low-grade dysplasia (adenoma) and moderate-grade dysplasia (borderline), or malignant, including high-grade dysplasia (carcinoma in situ) and invasive carcinoma. ${ }^{94,113} \mathrm{~A}$ second clinically important classification system for IPMN is based on the site and extent of the involved pancreatic duct. They can be divided into main-duct, branch-duct, or mixed-type IPMNs, ${ }^{114}$ although for management purposes, mixed-typed and main-duct lesions are often grouped together because they seem to behave in the same manner clinically. They account for more than half of all IPMNs, with most main-duct cases arising in the head of the pancreas and progressing distally with or without involvement of branch ducts. Branch-duct IPMNs account for the remaining cases and are typically found either in the uncinate process or in the tail of the pancreas. ${ }^{115}$

This anatomic distinction is important as main-duct IPMNs tend to be more aggressive than their branch-duct counterparts. They are more likely to be malignant on presentation and, if benign at that time, are more likely to turn malignant. ${ }^{116}$ Rates of malignancy (including carcinoma in situ) in main-duct IPMNs range from $60 \%$ to $92 \%$, with a mean of $70 \%$. Of these malignant neoplasms, almost two-thirds are invasive. By comparison, branch-duct IPMNs harbor malignancy in $6 \%$ to $46 \%$, with a mean of $25 \%$, and invasive carcinoma in $0 \%$ to $31 \%$, with a mean of $15 \%$ of all cases. ${ }^{87}$

\section{Diagnosis}

A diagnosis of IPMN must be achieved with good accuracy and often requires a combination of studies. Thin-slice CT is typically the initial imaging study of choice in the evaluation of IPMNs, which appear as a lobulated, poorly demarcated, polycystic mass associated with dilation of the main pancreatic duct or its side branches (Fig. 8). CT may also detect a protruding papilla and show a communication between the cysts and the ductal system. ${ }^{117}$ On imaging, certain features can delineate between the subtypes of IPMN: mural nodules within the main duct together with main-duct dilation greater than $10 \mathrm{~mm}$ suggest main-duct IPMN, whereas mucinous cysts that communicate with the pancreatic ductal 
system without main-duct dilation suggest branch-duct IPMN. A duct-cyst communication may be best identified using MRI with MRCP. ${ }^{78}$ Furthermore, MRCP may be more sensitive than ERCP in differentiating mural nodules from mucus and in studying the duct anatomy, as ERCP quality is negatively affected when intraductal mucin plugs obscure the filling of the pancreatic ducts. In addition, because it is a noninvasive study, MRCP would avoid the potential complications of ERCP. ${ }^{118}$ Cross-sectional findings suggestive of malignancy include ductal dilation greater than $10 \mathrm{~mm}$; mural nodules, especially if greater than $3 \mathrm{~mm}$ in size; presence of a solid component; and calcification of intraluminal contents. ${ }^{119}$ In a study by Irie and colleagues ${ }^{118}$ looking specifically at MRCP, findings of filling defects, diffuse main pancreatic duct dilation greater than $15 \mathrm{~mm}$ in main-duct IPMN, and any main pancreatic duct dilation in branch-duct IPMN, were strongly associated with malignancy.

EUS is often used either to confirm findings or to follow up inconclusive data from other studies and can show fine structures, especially when combined with ERCP, which is considered by some the gold standard for the diagnosis of IPMN. ${ }^{117,120}$ The appearance of IPMN on imaging is that of a "bunch of grapes," with cysts lying side by side, in contrast to the cyst-in-cyst appearance of MCNs. Typical findings in main-duct lesions include segmental or diffuse dilation of the main pancreatic duct, without strictures, and the presence of mural nodules. There may or may not be dilation of side branches. Filling defects are often seen in the pancreatic duct secondary to either mucous globules or papillary mural nodules. For branch-duct IPMNs, multiple small cysts are often found that communicate with the pancreatic ductal system. On ERCP, the ampulla of Vater is frequently found to be patulous with a characteristic "fish-mouth" appearance, often with mucin extruding from the papilla. In addition, ERCP allows collection of cytology specimens by either aspiration of duct contents or brushings, and can play a therapeutic role by clearing mucus from the duct. ${ }^{121}$

A newer diagnostic tool in the clinician's arsenal is peroral pancreatoscopy combined with intraductal ultrasonography. ${ }^{122}$ The pancreatoscope is usually easily cannulated through the dilated pancreatic duct and ampullary orifice, and may allow for direct biopsy, improved differentiation between malignant and benign disease, and determination of the optimal treatment approach. Findings on pancreatoscopy that suggest malignancy include spotty or linear red markings, fish egg-like lesions, villous proliferations, and vegetative-type lesions. ${ }^{123}$ However, experience with these modalities is still limited.

Cytology is considered by some a necessary part of the diagnostic work-up for IPMN as some lesions that would have been candidates for nonoperative management by current guidelines have been found to contain either high-grade dysplasia or invasive carcinoma requiring resection on cytology. ${ }^{99}$ However, as with MCNs, cytology may be misleading because of sampling errors in IPMNs, as they can often bear areas of invasion intermingled with benign epithelium; only a complete histopathologic evaluation of the entirely resected specimen can definitively determine the aggressiveness of the tumor. ${ }^{83} \mathrm{In}$ addition to cytology, pancreatic fluid may also be evaluated for molecular markers such as K-ras, p53, and telomerase activity, and tumor markers and amylase levels. CEA levels can readily distinguish mucinous neoplastic lesions from SCNs and pseudocysts, but cannot reliably 
determine whether they are MCNs or IPMNs, or whether they are benign or malignant. Although increased amylase levels can usually discriminate a pseudocyst from PCNs, IPMNs are the exception. Because they communicate with the pancreatic ductal system, IPMNs yield cyst fluid that contains high levels of amylase. ${ }^{21}$ For this reason, and because rare MCNs may communicate with the ductal system, amylase level alone is a poor discriminator of the different types of cysts. ${ }^{14}$

Although diagnostic tools are becoming increasingly accurate in the evaluation of IPMNs, preoperative differentiation between malignant and benign lesions still cannot be made with absolute certainty. Moreover, because up to a third of patients with IPMN suffer from pancreatic adenocarcinoma elsewhere in the gland or from extrapancreatic neoplasms, ${ }^{103,104}$ it is important to review all diagnostic images for suspicious lesions in the rest of the pancreas and in other organs also.

\section{Management}

Given their different clinicopathologic course, main-duct (including mixed-type) and branch-duct IPMNs are treated according to 2 different algorithms. The current recommended treatment of main-duct and mixed-type IPMNs is complete resection of all lesions, as long as the patient is a good surgical candidate with a reasonable life expectancy. ${ }^{87}$ This recommendation is based on the high risk of malignancy $(70 \%)$ associated with main-duct IPMN, and because most, if not all, benign main-duct or mixedtype IPMNs progress to invasive cancer within as few as 5 to 6 years. The recommendations for branch-duct IPMNs are less well defined because of a decreased risk of malignancy and progression to malignancy, thereby leaving room for conservative management in selected cases. Resection is recommended for patients with branch-duct IPMNs who (1) are symptomatic (eg, pancreatitis), for symptom relief, and because symptoms are suggestive of malignancy; (2) have dilation of the main pancreatic duct greater than $10 \mathrm{~mm}$; (3) have cyst size greater than $30 \mathrm{~mm}$; (4) have intramural nodules; or (5) have cytology suspicious or positive for malignancy. These factors have been found to be the strongest predictors of malignancy in branch-duct IPMNs. ${ }^{124,125}$ Thus, small, asymptomatic, simple branch-duct IPMNs can be managed conservatively with careful observation and periodic surveillance, with favorable survival. ${ }^{126}$

Although the main goals for surgical resection include the treatment of symptoms, removal of malignant lesions before they spread, and removal of benign lesions before they become malignant, it remains debatable as to which operation is best for the resection of IPMNs. Therefore, the operation performed must be tailored to each individual case depending on such factors as tumor size, location, presence of invasion, degree of dysplasia, or expected morbidity. Several studies have been performed to determine which type of resection provides the best outcomes. Chari and colleagues ${ }^{127}$ concluded from their study of recurrence after surgical resection of IPMNs that for invasive lesions, recurrence rates were similar after partial pancreatectomy (18 of 27 cases, 67\%) and total pancreatectomy ( 8 of 13 cases, $62 \%$ ). Jang and colleagues ${ }^{119}$ reached the same conclusion in their multicenter analysis of surgical outcomes for IPMNs, finding similar recurrence rates following total pancreatectomy (37.5\%) and partial pancreatic resections (32.5\%) for invasive disease. 
Moreover, these investigators found that most recurrences after total and partial pancreatectomies for invasive IPMNs were extrapancreatic metastases and not local recurrences. Total pancreatectomy thus not only fails to provide protection against distant recurrences or improve survival compared with partial pancreatectomies, it is also associated with significantly increased, and at times debilitating, morbidity. Total pancreatectomy causes complete exocrine and endocrine pancreatic insufficiency, resulting in diabetes, pancreatic malabsorption, and steatorrhea. Therefore, current guidelines recommend formal anatomic, oncologic partial resections with negative margins for all IPMNs, reserving total pancreatectomy for main-duct IPMNs with diffuse involvement of the pancreatic duct and, if necessary, for recurrent disease. ${ }^{13,87}$ Organ-sparing operations, such as spleen-preserving distal pancreatectomy or duodenum-sparing pancreatectomy, should be reserved for benign IPMNs, which require confirmation by negative intraoperative assessment. Limited pancreatic resections like enucleation, however, have no role in the management of IPMNs because of the high incidence of invasive disease. Whenever there is any doubt regarding the invasiveness of a lesion, it is recommended that a classic anatomic resection such as pancreaticoduodenectomy, distal pancreatectomy, or total pancreatectomy be performed together with lymph-node dissection, depending on the extent of disease. ${ }^{87}$

As with MCNs, survival after resection of IPMNs is most strongly correlated with the presence of invasive disease. Several studies have reported significantly greater 5-year survival rates for noninvasive (including carcinoma in situ) IPMNs than for their malignant counterparts, with rates ranging between $77 \%$ and $100 \%$ for the former and $31 \%$ and $46 \%$ for the latter. ${ }^{128-131}$ In 1 of those reports, Sohn and colleagues identified the presence of invasive carcinoma as the single strongest adverse predictor of survival. They further found that among patients with invasive disease, lymph-node status also carried predictive value and may be the main contributing factor to their poor outcome: among patients with invasive IPMN who underwent resection, the 1-2-, and 5-year survival rates were $45 \%, 24 \%$, and $0 \%$ for those with positive lymph nodes, compared with $95 \%, 95 \%$, and $85 \%$, respectively, for those with negative lymph nodes. ${ }^{128}$ Finally, the status of surgical margins was also found to be highly predictive of survival, as patients with surgical margins negative for invasive cancer showed a trend toward improved survival, with 1-, 2-, and 5- year actuarial survival rates of $78 \%, 62 \%$, and $46 \%$ compared with $40 \%, 0 \%$, and $0 \%$, respectively, for those with positive resection margins. ${ }^{128}$ This finding justifies the need for intraoperative frozen sections and reflects their critical importance in the management of IPMNs. The current international consensus guidelines on positive surgical margins are as follows. ${ }^{87}$ If margins are positive for adenoma or borderline atypia with minimal cytoarchitectural atypia and gastric/foveolar-type epithelium, no further resection is required. If instead they are positive for invasive carcinoma, carcinoma in situ, or borderline atypia exhibiting florid papilla formation, further resection is warranted, if feasible. ${ }^{132}$ In such instances, further "creeping" resection toward the head for a tail lesion, or toward the tail for a head or uncinate process lesion, can often be sufficient. In the rare instance that a negative margin cannot be attained in this manner, a total pancreatectomy may be required.

The decision to pursue conservative management rather than resection should be based on the age of the patient, the presence of comorbidities, the expected surgical morbidity, and the estimation of the risk of malignancy in the lesion. A thorough discussion with the patient 
is vital and must present the risk for malignancy and that of developing a malignancy. IPMNs that seem most amenable to conservative management from the limited data available are asymptomatic cystic lesions without dilation of the main pancreatic duct more than $6 \mathrm{~mm}$, those without mural nodules, and tumor size less than $30 \mathrm{~mm}$, as these lesions have a low risk of harboring malignancy or of developing a malignancy within the next 1 to 3 years. ${ }^{87,133}$ These guidelines have been tested by several studies, the results of which have supported their use and have found them to have a high sensitivity for predicting malignancy. ${ }^{134,135}$ If conservative management is chosen, the patient must undergo careful follow-up. According to the recommendations by Tanaka and colleagues, ${ }^{87}$ the time interval for follow-up should be 12 months for lesions less than $10 \mathrm{~mm}, 6$ to 12 months for lesions between 10 and $20 \mathrm{~mm}$, and 3 to 6 months for lesions greater than $20 \mathrm{~mm}$. For small lesions, thin-slice CT or MRCP should allow sufficient evaluation; however, for larger lesions (greater than $10 \mathrm{~mm}$ ), it is recommended that EUS be added to MRCP or ERCP. The follow-up interval can be lengthened after 2 years of no change. Indications for resection on follow-up studies include new onset of symptoms, development of intramural nodules, cyst size greater than $30 \mathrm{~mm}$, and main-duct dilation greater than $6 \mathrm{~mm}$.

Patients who have undergone surgical resection of a benign IPMN are still at risk of recurrence in the remaining pancreas and would benefit from further resection if this occurs. The recurrence rate for noninvasive IPMNs after partial pancreatic resection with negative margins is about 7\%, and these patients should receive close surveillance, with yearly CT or MRI. Patients with invasive IPMN are at a significantly higher risk of recurrence following resection, with recurrence rates between $50 \%$ and $90 \% .{ }^{13}$ These patients should be followed with CT or MRI every 6 months. ${ }^{87}$ Moreover, it is important to be mindful of the possibility of ductal adenocarcinoma or extrapancreatic neoplasms developing in all IPMN patients.

\section{Summary}

Cystic neoplasms of the pancreas are a diverse group of pancreatic tumors with differing pathophysiology, malignant potential, and clinical outcomes that warrant a thorough diagnostic algorithm and a tumor-specific therapeutic approach. In their evaluation, they must first be distinguished from inflammatory pseudocysts, and then from one another. This evaluation can usually be accomplished with a thorough history-taking, combined with a high-quality, contrast-enhanced, thin-cut abdominal CT. Additional diagnostic tools may be necessary and include MRCP, ERCP, and EUS-guided tumor biopsy and cyst aspiration. Cyst fluid should be sent for cytology, and measurement of tumor markers and amylase level. The combination of these modalities will usually allow clinicians to discriminate PCNs accurately (Table 1) and guide their management, although no diagnosis is definitive until or unless the entire tumor has been resected and completely histopathologically examined. PCNs should be categorized as serous tumors, consisting of SCNs, or mucinous tumors, made up of MCNs and IPMNs. SCNs are, for the most part, benign lesions that can be observed; indications for their resection include development of symptoms, rapid tumor growth, or changes in radiographic appearance, and inability to achieve a clear diagnosis. Once resected, no surveillance is necessary. MCNs are considered to have $100 \%$ malignant potential, and should be resected when identified. They affect women almost exclusively, and are distinguished from IPMNs by the presence of an ovarian-type stroma. MCNs require 
postresection surveillance only if they contain an invasive component. IPMNs, when possible, should be further subclassified as main-duct or branch-duct lesions. Main-duct IPMNs are more aggressive and should all be resected, whereas branch-duct IPMNs can be observed if small, simple, and asymptomatic, without main-duct dilation. Following resection, all patients with IPMNs require close surveillance because of high rates of recurrence. They are also at greater risk of developing an unrelated malignancy.

\section{Acknowledgments}

The authors would like to thank Dr Jennifer Kum of the Department of Pathology at the University of California, San Diego School of Medicine for providing the pathology pictures.

\section{References}

1. Compagno J, Oertel JE. Microcystic adenomas of the pancreas (glycogen-rich cystadenomas): a clinicopathologic study of 34 cases. Am J Clin Pathol. 1978; 69(3):289-98. [PubMed: 637043]

2. Compagno J, Oertel JE. Mucinous cystic neoplasms of the pancreas with overt and latent malignancy (cystadenocarcinoma and cystadenoma). A clinicopathologic study of 41 cases. Am J Clin Pathol. 1978; 69(6):573-80. [PubMed: 665578]

3. Ohhashi K, Murakimi Y, Maruyama M, et al. Four cases of mucous secreting pancreatic cancer. Prog Dig Endosc. 1982; 20:348-51. in Japanese.

4. Megibow AJ, Lombardo FP, Guarise A, et al. Cystic pancreatic masses: crosssectional imaging observations and serial follow-up. Abdom Imaging. 2001; 26(6):640-7. [PubMed: 11907731]

5. Spinelli KS, Fromwiller TE, Daniel RA, et al. Cystic pancreatic neoplasms: observe or operate. Ann Surg. 2004; 239(5):651-7. [PubMed: 15082969]

6. Zhang XM, Mitchell DG, Dohke M, et al. Pancreatic cysts: depiction on singleshot fast spin-echo MR images. Radiology. 2002; 223(2):547-53. [PubMed: 11997566]

7. Kimura W, Nagai H, Kuroda A, et al. Analysis of small cystic lesions of the pancreas. Int $\mathbf{J}$ Pancreatol. 1995; 18(3):197-206. [PubMed: 8708390]

8. Fernandez-del Castillo C, Warshaw AL. Cystic neoplasms of the pancreas. Pancreatology. 2001; 1(6):641-7. [PubMed: 12120248]

9. Brugge WR, Lauwers GY, Sahani D, et al. Cystic neoplasms of the pancreas. N Engl J Med. 2004; 351(12):1218-26. [PubMed: 15371579]

10. Warshaw AL, Rutledge PL. Cystic tumors mistaken for pancreatic pseudocysts. Ann Surg. 1987; 205(4):393-8. [PubMed: 3566376]

11. Horvath KD, Chabot JA. An aggressive resectional approach to cystic neoplasms of the pancreas. Am J Surg. 1999; 178(4):269-74. [PubMed: 10587182]

12. Goh BK, Tan YM, Cheow PC, et al. Cystic lesions of the pancreas: an appraisal of an aggressive resectional policy adopted at a single institution during 15 years. Am J Surg. 2006; 192(2):148-54. [PubMed: 16860621]

13. Sarr MG, Murr M, Smyrk TC, et al. Primary cystic neoplasms of the pancreas. Neoplastic disorders of emerging importance - current state-of-the-art and unanswered questions. J Gastrointest Surg. 2003; 7(3):417-28. [PubMed: 12654569]

14. Martin I, Hammond P, Scott J, et al. Cystic tumours of the pancreas. Br J Surg. 1998; 85(11): 1484-6. [PubMed: 9823906]

15. Delcore R, Thomas JH, Forster J, et al. Characteristics of cystic neoplasms of the pancreas and results of aggressive surgical treatment. Am J Surg. 1992; 164(5):437-41. [PubMed: 1279997]

16. Habashi S, Draganov PV. Pancreatic pseudocyst. World J Gastroenterol. 2009; 15(1):38-47. [PubMed: 19115466]

17. Sarr MG, Kendrick ML, Nagorney DM, et al. Cystic neoplasms of the pancreas: benign to malignant epithelial neoplasms. Surg Clin North Am. 2001; 81(3):497-509. [PubMed: 11459267] 
18. Kloppel, G.; Solcia, E.; Longnecker, DS., et al. World Health Organization international histological classification of tumors. 2nd. Berlin: Springer; 1996. Histological typing of tumours of the exocrine pancreas; p. 15-21.

19. Le Borgne J, de Calan L, Partensky C. Cystadenomas and cystadenocarcinomas of the pancreas: a multiinstitutional retrospective study of 398 cases. French Surgical Association. Ann Surg. 1999; 230(2):152-61. [PubMed: 10450728]

20. Galanis C, Zamani A, Cameron JL, et al. Resected serous cystic neoplasms of the pancreas: a review of 158 patients with recommendations for treatment. J Gastrointest Surg. 2007; 11(7):820 6. [PubMed: 17440789]

21. Sakorafas GH, Sarr MG. Cystic neoplasms of the pancreas: what a clinician should know. Cancer Treat Rev. 2005; 31(7):507-35. [PubMed: 16257126]

22. Hutchins GF, Draganov PV. Cystic neoplasms of the pancreas: a diagnostic challenge. World J Gastroenterol. 2009; 15(1):48-54. [PubMed: 19115467]

23. Horaguchi J, Fujita N, Kobayashi G, et al. Serous cystadenoma of the pancreas associated with obstructive jaundice. J Gastroenterol. 2003; 38(5):501-6. [PubMed: 12768395]

24. Furukawa H, Takayasu K, Mukai K, et al. Serous cystadenoma of the pancreas communicating with a pancreatic duct. Int J Pancreatol. 1996; 19(2):141-4. [PubMed: 8723557]

25. Tseng JF, Warshaw AL, Sahani DV, et al. Serous cystadenoma of the pancreas: tumor growth rates and recommendations for treatment. Ann Surg. 2005; 242(3):413-9. [PubMed: 16135927]

26. Strobel O, Z'graggen K, Schmitz-Winnenthal FH, et al. Risk of malignancy in serous cystic neoplasms of the pancreas. Digestion. 2003; 68(1):24-33. [PubMed: 12949436]

27. George DH, Murphy F, Michalski R, et al. Serous cystadenocarcinoma of the pancreas: a new entity? Am J Surg Pathol. 1989; 13(1):61-6. [PubMed: 2909198]

28. Okada T, Nonami T, Miwa T, et al. Hepatic metastasis of serous cystadenocarcinoma resected 4 years after operation of primary tumors - a case report. Nippon Shokakibyo Gakkai Zasshi. 1991; 88(10):2719-23. in Japanese. [PubMed: 1758093]

29. Abe H, Kubota K, Mori M, et al. Serous cystadenoma of the pancreas with invasive growth: benign or malignant? Am J Gastroenterol. 1998; 93(10):1963-6. [PubMed: 9772066]

30. Compton CC. Serous cystic tumors of the pancreas. Semin Diagn Pathol. 2000; 17(1):43-55. [PubMed: 10721806]

31. Tarpila E, Borch K, Franzen L, et al. Cystic neoplasms of the pancreas: a clinicopathological study of 38 cases. Dig Surg. 1989; 6:138-41.

32. Nodell CG, Freeny PC, Dale DH, et al. Serous cystadenoma of the pancreas with a metachronous adenocarcinoma. AJR Am J Roentgenol. 1994; 162(6):1352-4. [PubMed: 8191997]

33. Hammel PR, Vilgrain V, Terris B, et al. Pancreatic involvement in von Hippel-Lindau disease. The Groupe Francophone d'Etude de la Maladie de von Hippel-Lindau Gastroenterology. 2000; 119(4):1087-95.

34. Kloppel G, Kosmahl M. Cystic lesions and neoplasms of the pancreas. The features are becoming clearer Pancreatology. 2001; 1(6):648-55.

35. Moore PS, Zamboni G, Brighenti A, et al. Molecular characterization of pancreatic serous microcystic adenomas: evidence for a tumor suppressor gene on chromosome 10q. Am J Pathol. 2001; 158(1):317-21. [PubMed: 11141506]

36. Vortmeyer AO, Lubensky IA, Fogt F, et al. Allelic deletion and mutation of the von Hippel-Lindau (VHL) tumor suppressor gene in pancreatic microcystic adenomas. Am J Pathol. 1997; 151(4): 951-6. [PubMed: 9327728]

37. Adsay NV. Cystic neoplasia of the pancreas: pathology and biology. J Gastrointest Surg. 2008; 12(3):401-4. [PubMed: 17957438]

38. Goh BK, Tan YM, Yap WM, et al. Pancreatic serous oligocystic adenomas: clinicopathologic features and a comparison with serous microcystic adenomas and mucinous cystic neoplasms. World J Surg. 2006; 30(8):1553-9. [PubMed: 16773248]

39. Egawa N, Maillet B, Schroder S, et al. Serous oligocystic and ill-demarcated adenoma of the pancreas: a variant of serous cystic adenoma. Virchows Arch. 1994; 424(1):13-7. [PubMed: 7526946] 
40. Warshaw AL, Compton CC, Lewandrowski K, et al. Cystic tumors of the pancreas. New clinical, radiologic, and pathologic observations in 67 patients Ann Surg. 1990; 212(4):432-43.

41. Procacci C, Graziani R, Bicego E, et al. Serous cystadenoma of the pancreas: report of 30 cases with emphasis on the imaging findings. J Comput Assist Tomogr. 1997; 21(3):373-82. [PubMed: 9135643]

42. Kim SY, Lee JM, Kim SH, et al. Macrocystic neoplasms of the pancreas: CT differentiation of serous oligocystic adenoma from mucinous cystadenoma and intraductal papillary mucinous tumor. AJR Am J Roentgenol. 2006; 187(5):1192-8. [PubMed: 17056905]

43. Nishihara K, Kawabata A, Ueno T, et al. The differential diagnosis of pancreatic cysts by MR imaging. Hepatogastroenterology. 1996; 43(9):714-20. [PubMed: 8799419]

44. Pyke CM, van Heerden JA, Colby TV, et al. The spectrum of serous cystadenoma of the pancreas. Clinical, pathologic, and surgical aspects Ann Surg. 1992; 215(2):132-9.

45. Centeno BA, Warshaw AL, Mayo-Smith W, et al. Cytologic diagnosis of pancreatic cystic lesions. A prospective study of 28 percutaneous aspirates. Acta Cytol. 1997; 41(4):972-80. [PubMed: 9250287]

46. Huang P, Staerkel G, Sneige N, et al. Fine-needle aspiration of pancreatic serous cystadenoma: cytologic features and diagnostic pitfalls. Cancer. 2006; 108(4):239-49. [PubMed: 16691573]

47. Albores-Saavedra J, Angeles-Angeles A, Nadji M, et al. Mucinous cystadenocarcinoma of the pancreas. Morphologic and immunocytochemical observations. Am J Pathol. 1987; 11(1):11-20.

48. Linder JD, Geenen JE, Catalano MF. Cyst fluid analysis obtained by EUS-guided FNA in the evaluation of discrete cystic neoplasms of the pancreas: a prospective single-center experience. Gastrointest Endosc. 2006; 64(5):697-702. [PubMed: 17055859]

49. van der Waaij LA, van Dullemen HM, Porte RJ. Cyst fluid analysis in the differential diagnosis of pancreatic cystic lesions: a pooled analysis. Gastrointest Endosc. 2005; 62(3):383-9. [PubMed: 16111956]

50. Salvia R, Festa L, Butturini G, et al. Pancreatic cystic tumors. Minerva Chir. 2004; 59(2):185-207. [PubMed: 15238892]

51. Talamini MA, Pitt HA, Hruban RH, et al. Spectrum of cystic tumors of the pancreas. Am J Surg. 1992; 163(1):117-24. [PubMed: 1733358]

52. Katz MH, Mortenson MM, Wang H, et al. Diagnosis and management of cystic neoplasms of the pancreas: an evidence-based approach. J Am Coll Surg. 2008; 207(1):106-20. [PubMed: 18589369]

53. Bassi C, Salvia R, Molinari E, et al. Management of 100 consecutive cases of pancreatic serous cystadenoma: wait for symptoms and see at imaging or vice versa? World J Surg. 2003; 27(3): 319-23. [PubMed: 12607059]

54. Lukish JR, Rothstein JH, Petruzziello M, et al. Spleen-preserving pancreatectomy for cystic pancreatic neoplasms. Am Surg. 1999; 65(6):596-9. [PubMed: 10366217]

55. Reese SA, Traverso LW, Jacobs TW, et al. Solid serous adenoma of the pancreas: a rare variant within the family of pancreatic serous cystic neoplasms. Pancreas. 2006; 33(1):96-9. [PubMed: 16804417]

56. Warshaw AL, Rattner DW, Fernandez-del Castillo C, et al. Middle segment pancreatectomy: a novel technique for conserving pancreatic tissue. Arch Surg. 1998; 133(3):327-31. [PubMed: 9517749]

57. Talamini MA, Moesinger R, Yeo CJ, et al. Cystadenomas of the pancreas: is enucleation an adequate operation? Ann Surg. 1998; 227(6):896-903. [PubMed: 9637553]

58. Kiely JM, Nakeeb A, Komorowski RA, et al. Cystic pancreatic neoplasms: enucleate or resect? J Gastrointest Surg. 2003; 7(7):890-7. [PubMed: 14592663]

59. Fernandez-del Castillo C, Targarona J, Thayer SP, et al. Incidental pancreatic cysts: clinicopathologic characteristics and comparison with symptomatic patients. Arch Surg. 2003; 138(4):427-33. [PubMed: 12686529]

60. Zamboni G, Scarpa A, Bogina G, et al. Mucinous cystic tumors of the pancreas: clinicopathological features, prognosis and relationship to other mucinous cystic tumors. Am J Surg Pathol. 1999; 23(4):410-22. [PubMed: 10199470] 
61. Wouters K, Ectors N, Van Steenbergen W, et al. A pancreatic mucinous cystadenoma in a man with mesenchymal stroma, expressing oestrogen and progesterone receptors. Virchows Arch. 1998; 432(2):187-9. [PubMed: 9504865]

62. de Calan L, Levrard H, Hennet H, et al. Pancreatic cystadenoma and cystadenocarcinoma: diagnostic value of preoperative morphological investigations. Eur J Surg. 1995; 161:35-40. [PubMed: 7727604]

63. Sarr, MG.; Prabhakar, LP.; Loftus, EV, Jr. The spectrum of cystic neoplasms including mucinous ductal ectasi. In: Dervenis, CG., editor. Advances in pancreatic disease. New York: Thieme; 1996. p. 352-70.

64. Le Borgne, J.; Bogomoletz, WV.; Vilgrain, V. Les cystadénomes mucineux. Les cystadénocarcinomes. In: Le Borgne, J.; de Calan, L.; Partensky, C., editors. Les tumeurs kystiques du pancréas. Paris: Arnette; 1997. p. 47-89.

65. Grieshop NA, Wiebke EA, Kratzer SS, et al. Cystic neoplasms of the pancreas. Am Surg. 1994; 60(7):509-14. [PubMed: 8010565]

66. Yamaguchi K, Ogawa Y, Chijiiwa K, et al. Mucin-hypersecreting tumors of the pancreas: assessing the grade of malignancy preoperatively. Am J Surg. 1996; 171(4):427-31. [PubMed: 8604836]

67. Solcia, E.; Capella, C.; Kloppel, G. Tumors of the pancreas. In: Rosai, J.; Sorbin, L., editors. Atlas of tumor pathology 3rd Series. Washington, DC: Armed Forces Institute of Pathology; 1997. p. 31-144.

68. Izumo A, Yamaguchi K, Eguchi T, et al. Mucinous cystic tumor of the pancreas: immunohistochemical assessment of "ovarian-type stroma". Oncol Rep. 2003; 10(3):515-25. [PubMed: 12684617]

69. Sakorafas, GH.; Sarr, MG. Cystic neoplasms of the pancreas. In: Bland, KI.; Sarr, MG., editors. The practice of general surgery. Philadelphia: WB Saunders; 2002. p. 771-6.

70. Bartsch D, Bastian D, Barth P, et al. K-ras oncogene mutations indicate malignancy in cystic tumors of the pancreas. Ann Surg. 1998; 228(1):79-86. [PubMed: 9671070]

71. Sarr MG, Carpenter HA, Prabhakar LP, et al. Clinical and pathologic correlation of 84 mucinous cystic neoplasms of the pancreas: can one reliably differentiate benign from malignant (or premalignant) neoplasms? Ann Surg. 2000; 231(2):205-12. [PubMed: 10674612]

72. Warshaw AL. Mucinous cystic tumors and mucinous ductal ectasia of the pancreas. Gastrointest Endosc. 1991; 37(2):199-201. [PubMed: 1851710]

73. Goh BK, Tan YM, Chung YF, et al. A review of mucinous cystic neoplasms of the pancreas defined by ovarian-type stroma: clinicopathological features of 344 patients. World J Surg. 2006; 30(12):2236-45. [PubMed: 17103100]

74. Reddy RP, Smyrk TC, Zapiach M, et al. Pancreatic mucinous cystic neoplasm defined by ovarian stroma: demographics, clinical features, and prevalence of cancer. Clin Gastroenterol Hepatol. 2004; 2(11):1026-31. [PubMed: 15551256]

75. Wilentz RE, Albores-Saavedra J, Zahurak M, et al. Pathologic examination accurately predicts prognosis in mucinous cystic neoplasms of the pancreas. Am J Surg Pathol. 1999; 23(11):1320-7. [PubMed: 10555000]

76. Allen PJ, D'Angelica M, Gonen M, et al. A selective approach to the resection of cystic lesions of the pancreas: results from 539 consecutive patients. Ann Surg. 2006; 244(4):572-82. [PubMed: 16998366]

77. Lee CJ, Scheiman J, Anderson MA, et al. Risk of malignancy in resected cystic tumors of the pancreas $\leq 3 \mathrm{~cm}$ in size: is it safe to observe asymptomatic patients? A multi-institutional report. J Gastrointest Surg. 2008; 12(2):234-42. [PubMed: 18040749]

78. Fukukura Y, Fujiyoshi F, Hamada H, et al. Intraductal papillary mucinous tumors of the pancreas. Comparison of helical CT and MR imaging. Acta Radiol. 2003; 44(5):464-71. [PubMed: 14510751]

79. Gress F, Gottlieb K, Cummings O, et al. Endoscopic ultrasound characteristics of mucinous cystic neoplasms of the pancreas. Am J Gastroenterol. 2000; 95(4):961-5. [PubMed: 10763945]

80. Sedlack R, Affi A, Vazquez-Sequeiros E, et al. Utility of EUS in the evaluation of cystic pancreatic lesions. Gastrointest Endosc. 2002; 56(4):543-7. [PubMed: 12297771] 
81. Edirimanne S, Connor SJ. Incidental pancreatic cystic lesions. World J Surg. 2008; 32(9):2028-37. [PubMed: 18553049]

82. Moparty B, Logrono R, Nealon WH, et al. The role of endoscopic ultrasound and endoscopic ultrasound-guided fine-needle aspiration in distinguishing pancreatic cystic lesions. Diagn Cytopathol. 2007; 35(1):18-25. [PubMed: 17173300]

83. Recine M, Kaw M, Evans DB, et al. Fine-needle aspiration cytology of mucinous tumors of the pancreas. Cancer. 2004; 102(2):92-9. [PubMed: 15098253]

84. Brugge WR. The mistletoe and cyst-fluid analysis: a sticky insight. Gastrointest Endosc. 2006; 64(5):703-4. [PubMed: 17055860]

85. Brugge WR, Lewandrowski K, Lee-Lewandrowski E, et al. Diagnosis of pancreatic cystic neoplasms: a report of the cooperative pancreatic cyst study. Gastroenterology. 2004; 126(5): 1330-6. [PubMed: 15131794]

86. Tann M, Sandrasegaran K, Jennings SG, et al. Positron-emission tomography and computed tomography of cystic pancreatic masses. Clin Radiol. 2007; 62(8):745-51. [PubMed: 17604762]

87. Tanaka M, Chari S, Adsay V, et al. International consensus guidelines for management of intraductal papillary mucinous neoplasms and mucinous cystic neoplasms of the pancreas. Pancreatology. 2006; 6(1-2):17-32. [PubMed: 16327281]

88. Lillemoe KD, Kaushal S, Cameron JL, et al. Distal pancreatectomy: indications and outcomes in 235 patients. Ann Surg. 1999; 229(5):693-8. [PubMed: 10235528]

89. Shoup M, Brennan MF, McWhite K, et al. The value of splenic preservation with distal pancreatectomy. Arch Surg. 2002; 137(2):164-8. [PubMed: 11822953]

90. Takada T, Yasuda H, Uchiyama K, et al. Duodenum-preserving pancreatoduodenectomy. A new technique for complete excision of the head of the pancreas with preservation of biliary and alimentary integrity. Hepatogastroenterology. 1993; 40(4):356-9. [PubMed: 8406305]

91. Fernandez-del Castillo C, Warshaw AL. Cystic tumors of the pancreas. Surg Clin North Am. 1995; 75(5):1001-16. [PubMed: 7660245]

92. Yeo CJ, Cameron JL, Sohn TA, et al. Six hundred fifty consecutive pancreaticoduodenectomies in the 1990s: pathology, complications, and outcomes. Ann Surg. 1997; 226(3):248-57. [PubMed: 9339931]

93. Ridder GJ, Maschek H, Klempnauer J. Favourable prognosis of cystadeno- over adenocarcinoma of the pancreas after curative resection. Eur J Surg Oncol. 1996; 22(3):232-6. [PubMed: 8654602]

94. Longnecker, DS.; Adler, G.; Hruban, RH., et al. Intraductal papillary-mucinous neoplasms of the pancreas. In: Hamilton, SR.; Aaltonen, LA., editors. Pathology and genetics of tumours of the digestive system WHO classification of tumors. Lyon: IARC Press; 2000. p. 237-41.

95. Sohn TA, Yeo CJ, Cameron JL, et al. Intraductal papillary mucinous neoplasms of the pancreas: an increasingly recognized clinicopathologic entity. Ann Surg. 2001; 234(3):313-21. [PubMed: 11524584]

96. McDonald JM, Williard W, Mais D, et al. The incidence of intraductal papillary mucinous tumors of the pancreas (1). Curr Surg. 2000; 57(6):610-4. [PubMed: 11120307]

97. Salvia R, Fernandez-del Castillo C, Bassi C, et al. Main-duct intraductal papillary mucinous neoplasms of the pancreas: clinical predictors of malignancy and long-term survival following resection. Ann Surg. 2004; 239(5):678-85. [PubMed: 15082972]

98. Gourgiotis S, Ridolfini MP, Germanos S. Intraductal papillary mucinous neoplasms of the pancreas. Eur J Surg Oncol. 2007; 33(6):678-84. [PubMed: 17207960]

99. Fritz S, Warshaw AL, Thayer SP. Management of mucin-producing cystic neoplasms of the pancreas. Oncologist. 2009; 14(2):125-36. [PubMed: 19211618]

100. Raut CP, Cleary KR, Staerkel GA, et al. Intraductal papillary mucinous neoplasms of the pancreas: effect of invasion and pancreatic margin status on recurrence and survival. Ann Surg Oncol. 2006; 13(4):582-94. [PubMed: 16523362]

101. Jeurnink SM, Vleggaar FP, Siersema PD. Overview of the clinical problem: facts and current issues of mucinous cystic neoplasms of the pancreas. Dig Liver Dis. 2008; 40(11):837-46. [PubMed: 18499541] 
102. Sugiyama M, Izumisato Y, Abe N, et al. Predictive factors for malignancy in intraductal papillary-mucinous tumours of the pancreas. Br J Surg. 2003; 90(10):1244-9. [PubMed: 14515294]

103. Yoon WJ, Ryu JK, Lee JK, et al. Extrapancreatic malignancies in patients with intraductal papillary mucinous neoplasm of the pancreas: prevalence, associated factors, and comparison with patients with other pancreatic cystic neoplasms. Ann Surg Oncol. 2008; 15(11):3193-8. [PubMed: 18784959]

104. Yamada M, Kozuka S, Yamao K, et al. Mucin-producing tumor of the pancreas. Cancer. 1991; 68(1):159-68. [PubMed: 2049738]

105. Wada K, Takada T, Yasuda H, et al. Does "clonal progression" relate to the development of intraductal papillary mucinous tumors of the pancreas. J Gastrointest Surg. 2004; 8(3):289-96. [PubMed: 15019925]

106. Adsay NV, Longnecker DS, Klimstra DS. Pancreatic tumors with cystic dilatation of the ducts: intraductal papillary mucinous neoplasms and intraductal oncocytic papillary neoplasms. Semin Diagn Pathol. 2000; 17(1):16-30. [PubMed: 10721804]

107. Chadwick B, Willmore-Payne C, Tripp S, et al. Histologic, immunohistochemical, and molecular classification of 52 IPMNs of the pancreas. Appl Immunohistochem Mol Morphol. 2009; 17(1): 31-9. [PubMed: 18813127]

108. Jang JY, Park YC, Song YS, et al. Increased K-ras mutation and expression of S100A4 and MUC2 protein in the malignant intraductal papillary mucinous tumor of the pancreas. $\mathrm{J}$ Hepatobiliary Pancreat Surg. 2009; 16(5):668-74. [PubMed: 19412570]

109. Uemura K, Hiyama E, Murakami Y, et al. Comparative analysis of K-ras point mutation, telomerase activity, and p53 overexpression in pancreatic tumours. Oncol Rep. 2003; 10(2):27783. [PubMed: 12579258]

110. Wada K. p16 and p53 gene alterations and accumulations in the malignant evolution of intraductal papillary-mucinous tumors of the pancreas. J Hepatobiliary Pancreat Surg. 2002; 9(1): 76-85. [PubMed: 12021900]

111. Fritz S, Fernandez-del Castillo C, Mino-Kenudson M, et al. Global genomic analysis of intraductal papillary mucinous neoplasms of the pancreas reveals significant molecular differences compared to ductal adenocarcinoma. Ann Surg. 2009; 239(3):440-7. [PubMed: 19247032]

112. Tanaka M, Kobayashi K, Mizumoto K, et al. Clinical aspects of intraductal papillary mucinous neoplasm of the pancreas. J Gastroenterol. 2005; 40(7):669-75. [PubMed: 16082582]

113. Adsay NV, Conlon KC, Zee SY, et al. Intraductal papillary-mucinous neoplasms of the pancreas: an analysis of in situ and invasive carcinomas in 28 patients. Cancer. 2002; 94(1):62-77. [PubMed: 11815961]

114. Hruban RH, Takaori K, Klimstra DS, et al. An illustrated consensus on the classification of pancreatic intraepithelial neoplasia and intraductal papillary mucinous neoplasms. Am J Surg Pathol. 2004; 28(8):977-87. [PubMed: 15252303]

115. Levy P, Jouannaud V, O'Toole D, et al. Natural history of intraductal papillary mucinous tumors of the pancreas: actuarial risk of malignancy. Clin Gastroenterol Hepatol. 2006; 4(4):460-8. [PubMed: 16616351]

116. Serikawa M, Sasaki T, Fujimoto Y, et al. Management of intraductal papillarymucinous neoplasm of the pancreas: treatment strategy based on morphologic classification. J Clin Gastroenterol. 2006; 40(9):856-62. [PubMed: 17016145]

117. Visser BC, Muthusamay VR, Mulvihill SJ, et al. Diagnostic imaging of cystic pancreatic neoplasms. Surg Oncol. 2004; 13(1):27-39. [PubMed: 15145031]

118. Irie H, Honda $\mathrm{H}$, Aibe $\mathrm{H}$, et al. MR cholangiopancreatographic differentiation of benign and malignant intraductal mucin-producing tumors of the pancreas. AJR Am J Roentgenol. 2000; 174(5):1403-8. [PubMed: 10789803]

119. Jang JY, Kim SW, Ahm YJ, et al. Multicenter analysis of clinicopathologic features of intraductal papillary mucinous tumor of the pancreas: is it possible to predict the malignancy before surgery? Ann Surg Oncol. 2005; 12(2):124-32. [PubMed: 15827792] 
120. Kubo H, Chijiwa Y, Kazuya A, et al. Intraductal papillary-mucinous tumors of the pancreas: differential diagnosis between benign and malignant tumors by endoscopic ultrasonography. Am J Gastroenterol. 2001; 96:1429-34. [PubMed: 11374678]

121. Cellier C, Cuillerier E, Palazzo L, et al. Intraductal papillary and mucinous tumors of the pancreas: accuracy of preoperative computed tomography, endoscopic retrograde pancreatography and endoscopic ultrasonography, and long-term outcome in a large surgical series. Gastrointest Endosc. 1998; 47(1):42-9. [PubMed: 9468422]

122. Yamao K, Okubo K, Sawaka A, et al. Endoluminal ultrasonography in the diagnosis of pancreatic diseases. Abdom Imaging. 2003; 28(4):545-55. [PubMed: 14580099]

123. Hara T, Yamaguchi T, Ishibara T, et al. Diagnosis and patient management of intraductal papillary mucinous tumor of the pancreas by using peroral pancreatoscopy and intraductal ultrasonography. Gastroenterology. 2002; 122(1):34-43. [PubMed: 11781278]

124. Sugiyama M, Suzuki Y, Abe N, et al. Management of intraductal papillary mucinous neoplasm of the pancreas. J Gastroenterol. 2008; 43(3):181-5. [PubMed: 18373159]

125. Waters JA, Schmidt CM. Intraductal papillary mucinous neoplasm - when to resect? Adv Surg. 2008; 42:87-108. [PubMed: 18953811]

126. Matsumoto T, Aramaki M, Yada K, et al. Optimal management of the branch duct type intraductal papillary mucinous neoplasms of the pancreas. J Clin Gastroenterol. 2003; 36(3):2615. [PubMed: 12590239]

127. Chari ST, Yadav D, Smyrk TC, et al. Study of recurrence after surgical resection of intraductal papillary mucinous neoplasm of the pancreas. Gastroenterology. 2002; 123(5):1500-7. [PubMed: 12404225]

128. Sohn TA, Yeo CJ, Cameron JL, et al. Intraductal papillary mucinous neoplasms of the pancreas: an updated experience. Ann Surg. 2004; 239(6):788-97. [PubMed: 15166958]

129. Wada K, Kozarek RA, Traverso LW. Outcomes following resection of invasive and noninvasive intraductal papillary mucinous neoplasms of the pancreas. Am J Surg. 2005; 189(5):632-6. [PubMed: 15862510]

130. Maire F, Hammel P, Terris B, et al. Prognosis of malignant intraductal papillary mucinous tumours of the pancreas after surgical resection. Comparison with pancreatic ductal adenocarcinoma Gut. 2002; 51(5):717-22.

131. Schnelldorfer T, Sarr MG, Nagorney DM, et al. Experience with 208 resections for intraductal papillary mucinous neoplasm of the pancreas. Arch Surg. 2008; 143(7):639-46. [PubMed: 18645105]

132. Adsay NV, Merati K, Basturk O, et al. Pathologically and biologically distinct types of epithelium in intraductal papillary mucinous neoplasms: delineation of an "intestinal" pathway of carcinogenesis in the pancreas. Am J Surg Pathol. 2004; 28(7):839-48. [PubMed: 15223952]

133. Woo SM, Ryu JK, Lee SH, et al. Branch-duct intraductal papillary mucinous neoplasms in a retrospective series of 190 patients. Br J Surg. 2009; 96(4):405-11. [PubMed: 19283746]

134. Nagai K, Doi R, Ito T, et al. Single-institution validation of the international consensus guidelines for treatment of branch-duct intraductal papillary mucinous neoplasms of the pancreas. J Hepatobiliary Pancreat Surg. 2009; 16(3):353-8. [PubMed: 19280108]

135. Salvia R, Crippa S, Falconi M, et al. Branch-duct intraductal papillary mucinous neoplasms of the pancreas: to operate or not to operate? Gut. 2007; 56(8):1086-90. [PubMed: 17127707] 


\section{Box 1}

\section{Differential diagnosis of pancreatic cystic lesions}

Nonneoplastic lesions

Inflammatory pseudocysts

Infectious cysts

Congenital cysts

Duplication cysts

Retention cysts

Lymphoepithelial cysts

Neoplastic lesions

Serous

Serous cystadenoma (SCA)

Serous cystadenocarcinoma (SCAC)

Mucinous

Mucinous cystic neoplasm (MCN; adenoma-carcinoma sequence)

Intraductal papillary mucinous neoplasm (IPMN; adenoma-carcinoma sequence)

Solid pseudopapillary tumor

Cystic variants of solid tumors

Cystic ductal adenocarcinoma

Cystic neuroendocrine tumor

Cystic acinar cell carcinoma 


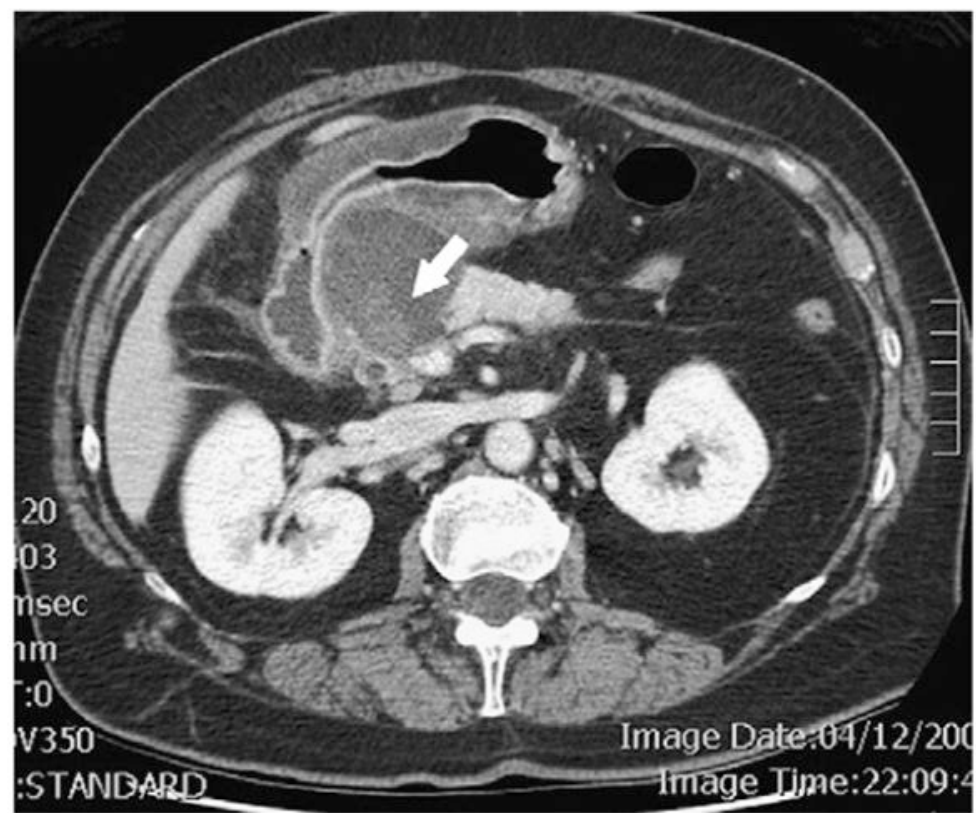

Fig. 1.

Abdominal CT of a patient with a history of pancreatitis presenting with abdominal tenderness. A pseudocyst is identified in the head of the pancreas that contains internal debris (arrow); note that it is thick walled and well circumscribed. 


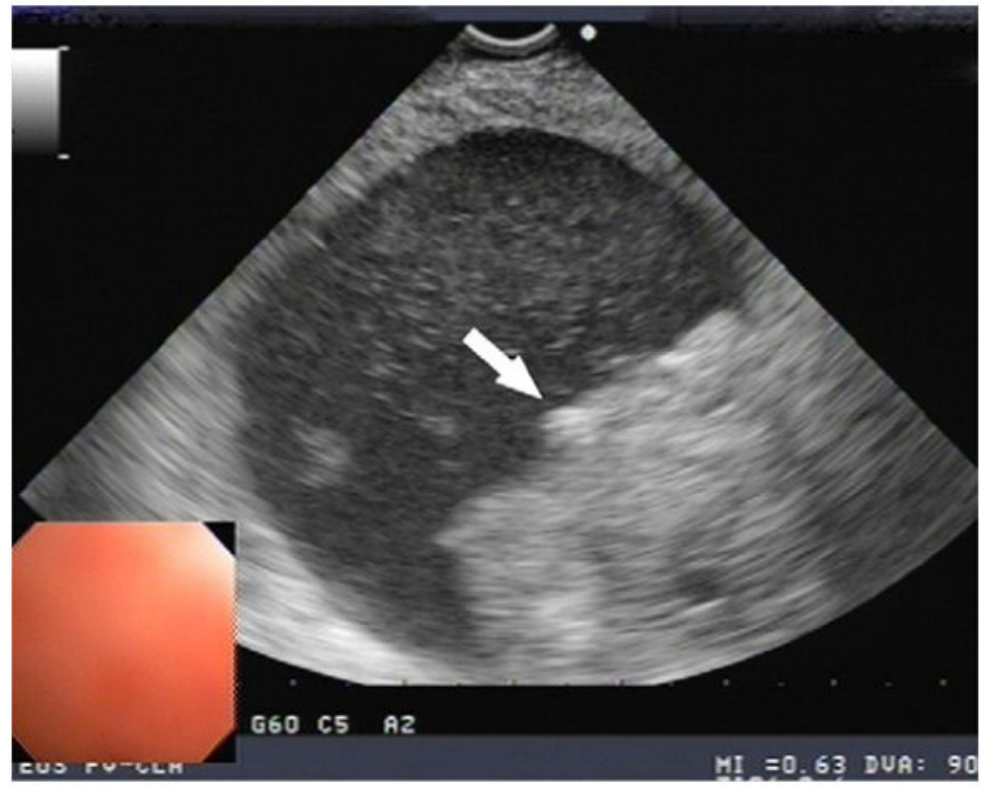

Fig. 2.

Ultrasound image of the pancreatic pseudocyst seen in Fig. 1 clearly shows internal debris (arrow) that shifts position within the cyst in a dependent manner with patient movement. 

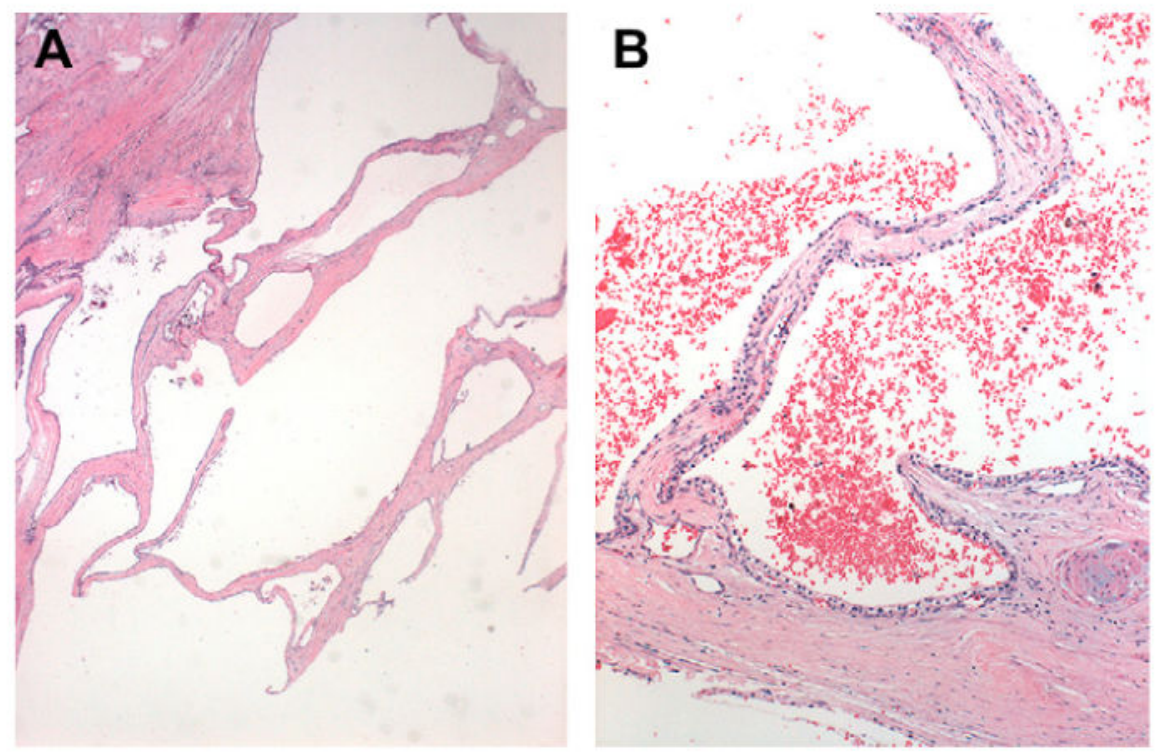

Fig. 3.

Hematoxylin and eosin stain of an SCA. (A) Multiple cysts are separated by thin fibrous bands. $(B)$ The cysts are lined by a uniform layer of cuboidal cells with round nuclei, best appreciated under higher magnification. 


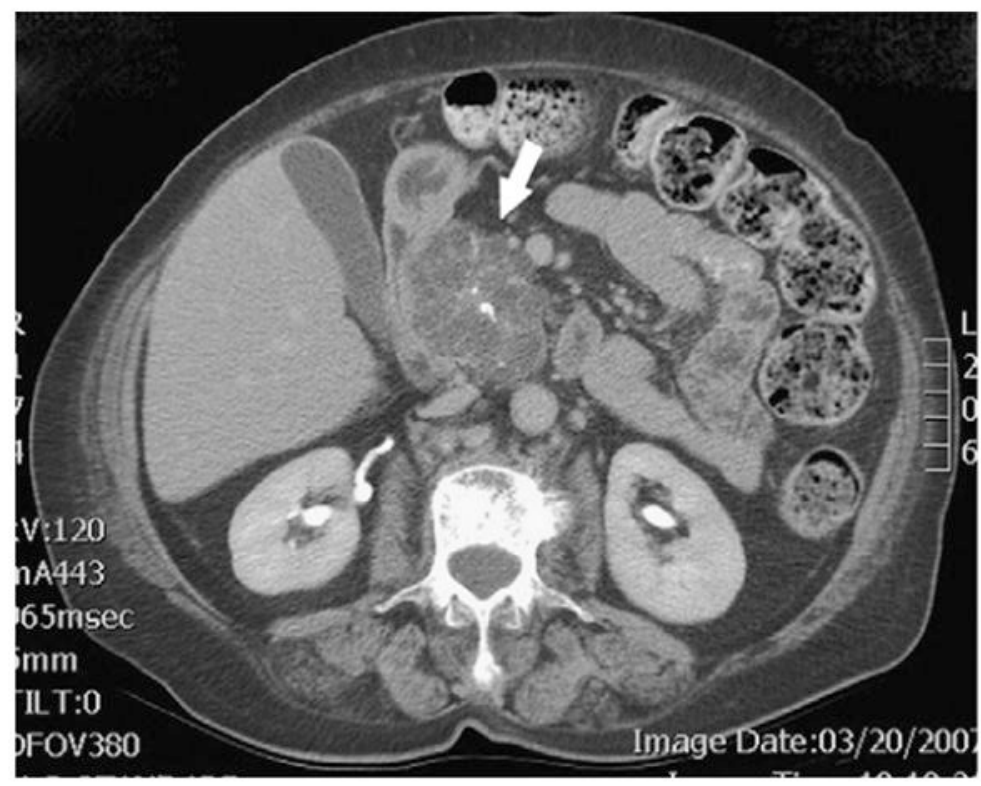

Fig. 4.

Abdominal CT of an 80-year-old woman with abdominal pain, nausea, and vomiting. A polycystic tumor in the head of the pancreas is detected that contains multiple small cysts separated by internal septations with a calcified central scar (arrow). These features are characteristic of an SCN. 

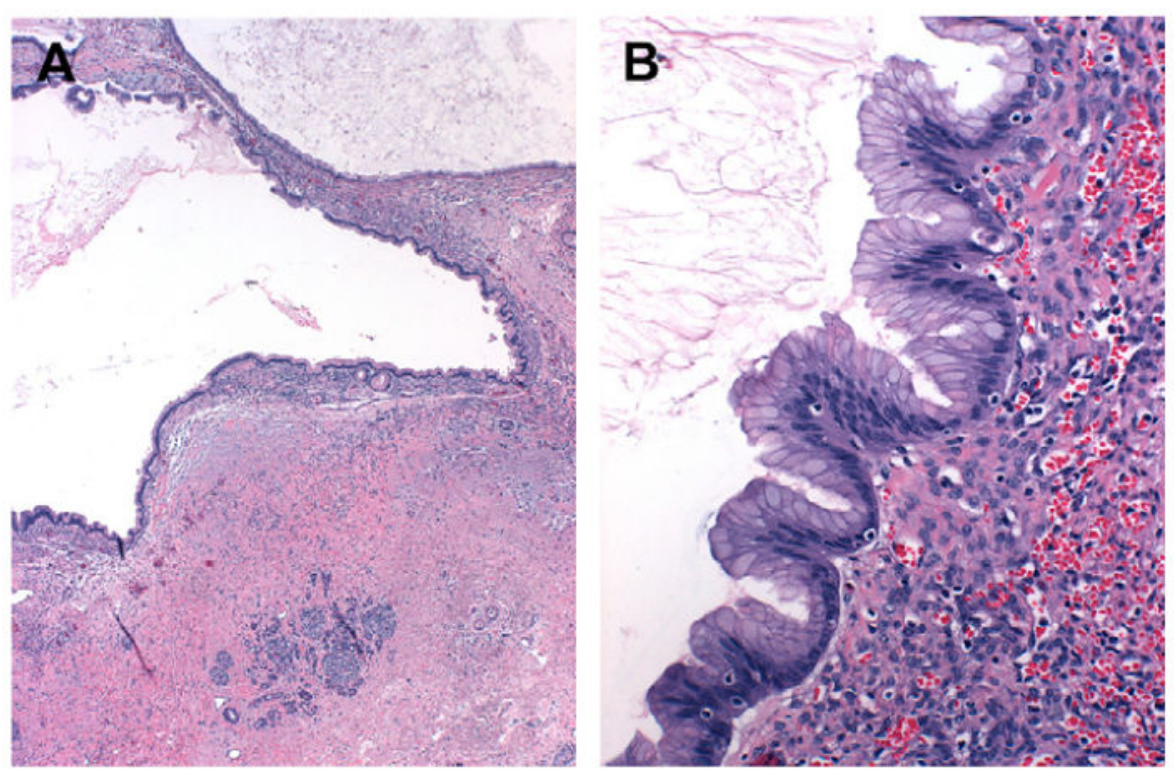

Fig. 5.

Hematoxylin and eosin stain of an MCN. (A) A hypercellular ovarian-type stroma is identified that underlies $(B)$ an epithelial lining consisting of columnar mucin-secreting cells. 


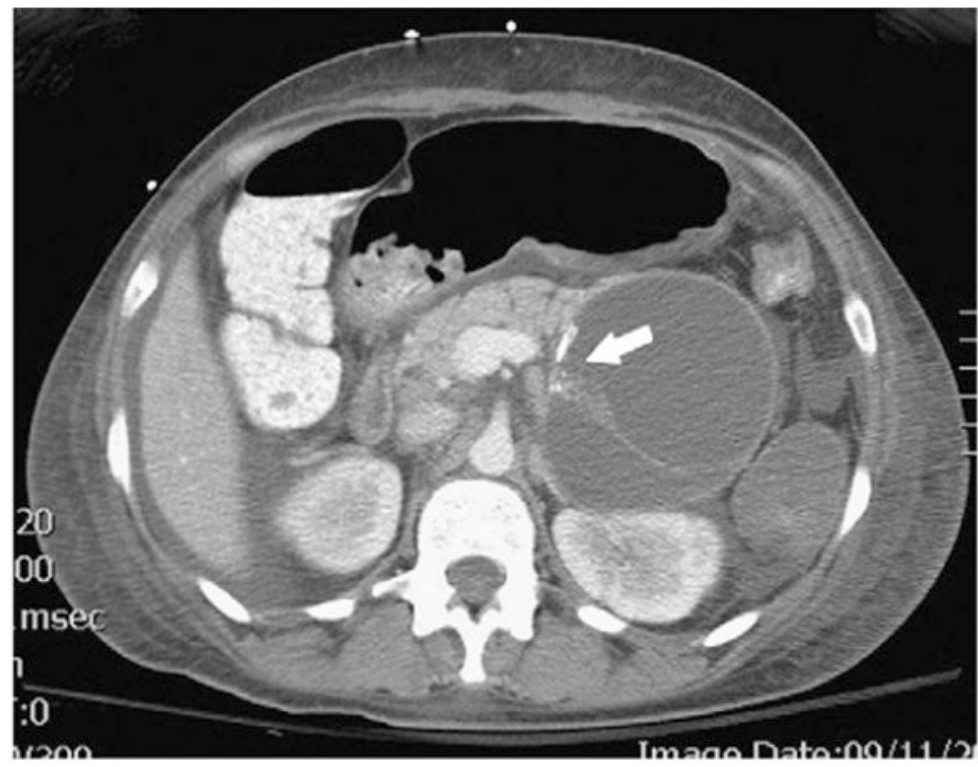

Fig. 6.

Abdominal CT of a 42-year-old woman performed for follow-up of her non-Hodgkin lymphoma reveals a thick-walled, well-demarcated, septated macrocyst with calcifications visible on 1 side of the cyst wall (arrow) in the tail of the pancreas. A distal pancreatectomy with splenectomy was performed for this suspected MCN. Final pathology report confirms the diagnosis of MCN of borderline malignant potential. 

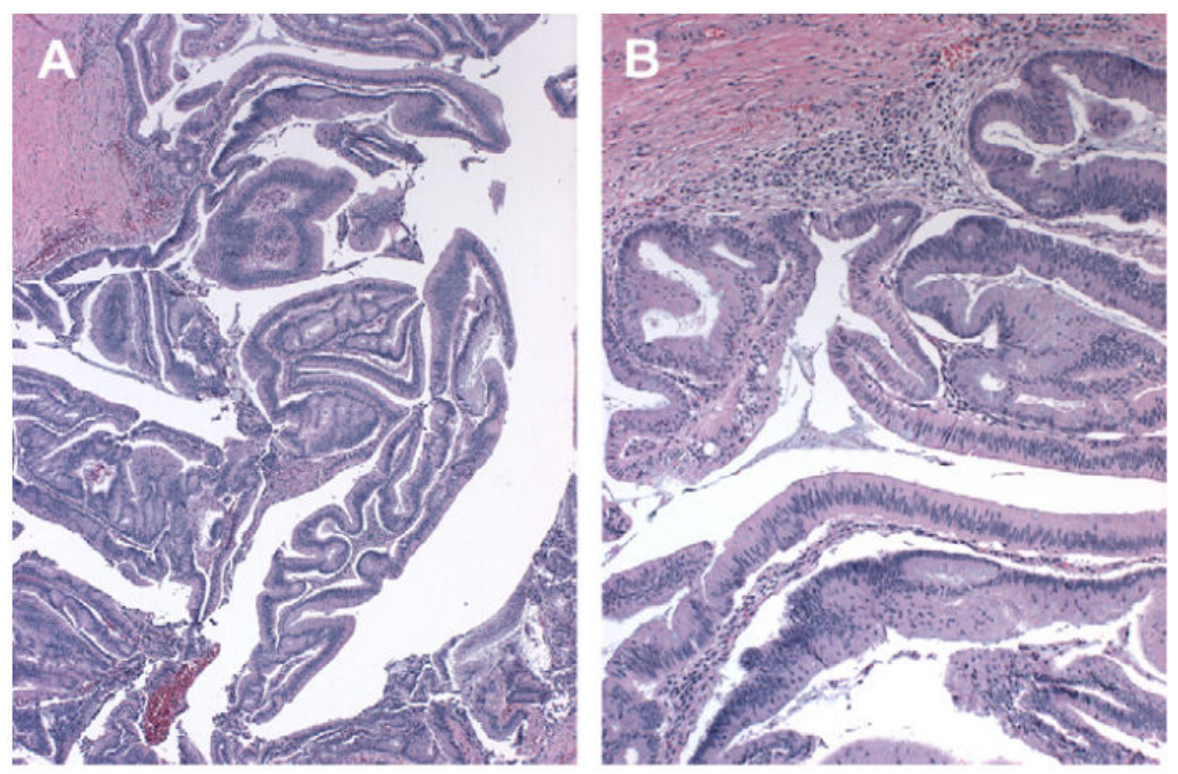

Fig. 7.

Characteristic hematoxylin and eosin stain of an IPMN shows (A) numerous wellformed papillary projections lacking an ovarian-type stroma. $(B)$ The papillae are lined by tall, columnar mucin-producing epithelial cells displaying a broad range of dysplastic changes. 


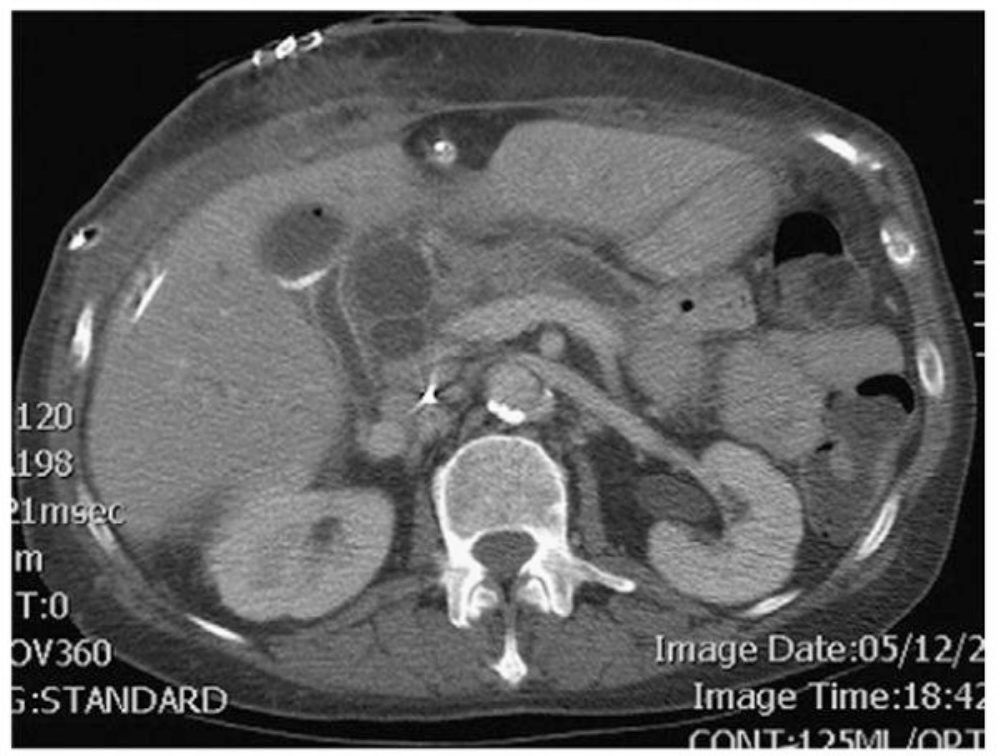

Fig. 8.

Abdominal CT of a 63-year-old patient who had presented 3 months earlier with abdominal pain and jaundice and was believed to have cholecystitis. The CT reveals a diffusely dilated pancreatic duct, along with intra- and extrahepatic biliary duct dilation. These findings are consistent with the diagnosis of IPMN. A total pancreatectomy with lymphadenectomy was performed; final pathology showed no evidence of invasion. 
Table 1

Defining characteristics of pseudocysts and PCNs

\begin{tabular}{|c|c|c|c|c|}
\hline Characteristics & Pseudocyst & SCA & MCN & IPMN \\
\hline \multicolumn{5}{|l|}{ Epidemiology } \\
\hline Gender & $\mathrm{F}=\mathrm{M}$ & $\mathrm{F} \gg \mathrm{M}(4: 1)$ & $\mathrm{F} \ggg \mathrm{M}(10: 1)$ & $\mathrm{F}=\mathrm{M}$ \\
\hline Age (years) & $40-60$ & $60-70$ & $50-60$ & $60-70$ \\
\hline \multicolumn{5}{|l|}{ Imaging findings } \\
\hline Location & Evenly distributed & Evenly distributed & Head $\ll$ body $/$ tail & $\begin{array}{l}\text { Head > diffuse > } \\
\text { body/tail }\end{array}$ \\
\hline Appearance & $\begin{array}{l}\text { Round, thick-walled } \\
\text { large cyst; gland atrophy } \\
\pm \text { calcification }\end{array}$ & $\begin{array}{l}\text { Multiple small cysts } \\
\text { separated by internal } \\
\text { septations with central } \\
\text { starburst calcifications }\end{array}$ & $\begin{array}{l}\text { Thick-walled, septated } \\
\text { macrocyst with smooth } \\
\text { contour; } \pm \text { solid } \\
\text { component, egg-shell } \\
\text { calcifications }\end{array}$ & $\begin{array}{l}\text { Poorly demarcated, } \\
\text { lobulated, polycystic } \\
\text { mass with dilation of } \\
\text { main or branch ducts }\end{array}$ \\
\hline Communication with ducts & Yes & No & Very rare & Yes \\
\hline \multicolumn{5}{|l|}{ Cyst fluid analysis } \\
\hline Cytology & Inflammatory cells & $\begin{array}{l}\text { Scant glycogen-rich cells, } \\
\text { with positive Periodic Acid } \\
\text { Schiff stain }\end{array}$ & $\begin{array}{l}\text { Sheets and clusters of } \\
\text { columnar, mucin- } \\
\text { containing cells }\end{array}$ & $\begin{array}{l}\text { Tall, columnar } \\
\text { mucin-containing } \\
\text { cells }\end{array}$ \\
\hline Mucin stain & Negative & Negative & Positive & Positive \\
\hline Amylase & Very high & Low & Low & High \\
\hline CEA & Low & Low & High & High \\
\hline
\end{tabular}

